\title{
Tree frog attachment: mechanisms, challenges, and perspectives
}

\author{
Julian K. A. Langowski ${ }^{*}$ (D), Dimitra Dodou² (D, Marleen Kamperman ${ }^{3}$ (D) and Johan L. van Leeuwen ${ }^{1}$ (D)
}

\begin{abstract}
Tree frogs have the remarkable ability to attach to smooth, rough, dry, and wet surfaces using their versatile toe pads. Tree frog attachment involves the secretion of mucus into the pad-substrate gap, requiring adaptations towards mucus drainage and pad lubrication. Here, we present an overview of tree frog attachment, with focus on (i) the morphology and material of the toe pad; (ii) the functional demands on the toe pad arising from ecology, lifestyle, and phylogenetics; (iii) experimental data of attachment performance such as adhesion and friction forces; and (iv) potential perspectives on future developments in the field. By revisiting reported data and observations, we discuss the involved mechanisms of attachment and propose new hypotheses for further research. Among others, we address the following questions: Do capillary and hydrodynamic forces explain the strong friction of the toe pads directly, or indirectly by promoting dry attachment mechanisms? If friction primarily relies on van der Waals (vdW) forces instead, how much do these forces contribute to adhesion in the wet environment tree frogs live in and what role does the mucus play? We show that both pad morphology and measured attachment performance suggest the coaction of several attachment mechanisms (e.g. capillary and hydrodynamic adhesion, mechanical interlocking, and $v d W$ forces) with situation-dependent relative importance. Current analytical models of capillary and hydrodynamic adhesion, caused by the secreted mucus and by environmental liquids, do not capture the contributions of these mechanisms in a comprehensive and accurate way. We argue that the soft pad material and a hierarchical surface pattern on the ventral pad surface enhance the effective contact area and facilitate gap-closure by macro- to nanoscopic drainage of interstitial liquids, which may give rise to a significant contribution of vdW interactions to tree frog attachment. Increasing the comprehension of the complex mechanism of tree frog attachment contributes to a better understanding of other biological attachment systems (e.g. in geckos and insects) and is expected to stimulate the development of a wide array of bioinspired adhesive applications.
\end{abstract}

Keywords: Toe pad, Attachment organ, Bioadhesion, Biotribology, Capillary adhesion, van der Waals, Drainage, Lubrication, Biomimetics, Litoria caerulea

\section{Background}

Strong, reversible, and repeatable grip to diverse substrates is a basic requirement for climbing animals [1]. A wide range of attachment organs fulfilling this requirement has evolved in animals such as insects [2], reptiles $[3,4]$, arachnids [5], and amphibians including tree [6] and torrent frogs [7]. The research on torrent frogs is relatively new and limited to a few studies [8-12], and thus this review focusses on tree frogs.

*Correspondence: julian.langowski@wur.nl

${ }^{1}$ Experimental Zoology Group, Department of Animal Sciences, Wageningen University \& Research, De Elst 1, 6708 WD Wageningen, The Netherlands Full list of author information is available at the end of the article
With their toe pads, tree frogs attach to a wide range of substrates, from smooth glass to rough wood [13] in both dry and wet environments [10]. Tree frogs are a polyphyletic group [14-17], but the basic morphology of their toe pads is consistent among frog families-a sign of convergent evolution [18-21]: the pads are soft (with an effective elastic modulus of ca. $20 \mathrm{kPa}$; e.g. [22]) and ventrally covered with a hierarchical, micro- to nanoscopic pattern of prismatic, epidermal cells separated by channels [23].

Several attachment mechanisms have been proposed for tree frogs' toe pads (e.g. $[6,24,25])$. The prevailing hypothesis is that adhesion (i.e. the attachment force normal to the substrate surface) is induced by mucus that 
is present at the pad-substrate interface, leading to capillary and hydrodynamic forces (i.e. wet adhesion). Furthermore, intermolecular interactions (i.e. van der Waals [vdW] forces) and mechanical interlocking have been suggested to contribute to both adhesion and friction (i.e. the attachment force parallel to the substrate surface) [24] ${ }^{1}$.

Despite the substantial progress made in the understanding of tree frog attachment over the last centuries, several questions remain unanswered. For example, do capillary and hydrodynamic forces explain the strong friction of the toe pads directly, or indirectly by promoting dry attachment mechanisms? If friction primarily relies on vdW forces instead, how much do these forces contribute to adhesion in the wet environment tree frogs live in and what is the function of the mucus? Are there other attachment mechanisms active in the toe pads and how do these mechanisms interact? Several questions concerning the functional morphology of the attachment apparatus also remain open. Can the smooth soft toe pads of tree frogs conform closely to rough substrates to form a large area of dry contact and strong vdW forces, as described for the hairy attachment organs of geckos $[26,27]$ and for the soft technical adhesives inspired thereof [28-30]? Do the structures on (and in) the ventral epidermis support force generation and how are contact forces transmitted to other body parts? Do internal pad structures facilitate the spatial distribution of mechanical stresses or of energy?

We discuss these questions by revisiting evidence regarding the attachment performance of tree frogs or, when information is lacking, formulate new hypotheses for further research. First, we describe the morphology and material properties of the toe pads. Subsequently, a set of functional demands regarding adhesion and friction, which the toe pad presumably accommodates, is presented as well as the physical fundamentals of the mechanisms that have been proposed in previous research to explain tree frog attachment. Next, we discuss the observed attachment performance of tree frogs with respect to the stated questions, the functional demands, the morphological and material properties of the pad, and the physical fundamentals of attachment. Finally, we present conclusions of the reviewed knowledge available on tree frog attachment and provide perspectives for potential future developments in the field.

\section{Morphology and material properties of a toe pad}

In this section, we describe the morphology of the limbs of tree frogs from the macroscopic anatomy (Fig. 1 $\mathrm{A}_{1}$ ) down to the nanoscopic features of the toe pad epidermis (Fig. $1 \mathrm{D}_{2}$ ). To get insight in where and how contact forces are generated, we categorise the morphological elements based on their potential functionality (e.g. attachment control and force transmission). Furthermore, we discuss the material properties of the pad and the secreted mucus.
For open questions on the pad morphology (and for possible approaches to answer these), we refer to the final section.

\section{Functional morphology of limbs and toes}

The tip of a tree frog's digit consists of the terminal phalanx, dermis, and epidermis (Fig. $1 \mathrm{~B}_{2}$; $[23,31$, 32]). The dermis contains connective tissue, blood vessels, lymph space, mucus glands, as well as muscle and nerve fibres (Fig. $1 \mathrm{~B}_{2}$; $[23,33,34]$ ). The ventral epidermis constitutes the actual toe pad [32]. The surface area $A_{\mathrm{p}}$ of single pads was reported by Linnenbach ([35]; Hyla cinerea, $0.82-1.21 \mathrm{~mm}^{2}$ ), Ba-Omar et al. ([36]; Phyllomedusa trinitatis, pad diameter $d_{\mathrm{p}}$ forelimb: $2.81 \mathrm{~mm}, d_{\mathrm{p}}$ hindlimb: $2.47 \mathrm{~mm}$ ), Mizuhira ([37]; two Rhacophoridae, $A_{\mathrm{p}}=2.5 \mathrm{~mm} \cdot 1.8 \mathrm{~mm}$ ), Chakraborti et al. ([38]; Philautus annandalii, $d_{\mathrm{p}}=1.2-1.5 \mathrm{~mm}$ ), and Endlein et al. ([39]; Rhacophorus dennysi, 2.1-4.7 $\mathrm{mm}^{2}$ ). The projected surface area $A$ of all pads of an individual frog scales nearly isometrically with snout-vent-length $\ell_{\mathrm{SV}}\left(A \propto \ell_{\mathrm{SV}}{ }^{1.76-2.29} ;[40-42]\right)$ and with body mass $m$ $\left(A \propto m^{0.68} ;\right.$ [43]).

\section{Contact geometry}

The distal portions of the toes are dilated [24, 44] and typically disc-shaped (Fig. 1B ; $_{1}$ [36]). The unloaded ventral toe pad surface is convex $[45,46]$, with a radius of curvature $R$ of $0.72-1.57 \mathrm{~mm}$ in juveniles and $4.07-5.81 \mathrm{~mm}$ in adults of Litoria caerulea [47]. Gu et al. [48] suggested that the ball-on-flat arrangement of the curved pad on a flat substrate protects the pad from misalignment. Moreover, a curved pad might require less energy for active alignment of the pad with respect to the substrate. The ventral pad surface is divided into subunits forming a hierarchical surface pattern:

Macroscale In several species, grooves following the proximal-distal axis separate the pad surface, and a circumferential groove forms the lateroterminal pad boundary between proximal (squamous) and distal (columnar) ventral epidermis (e.g. [8, 18, 20, 32, 33, 49]).

Microscale Prismatic cells on the ventral epidermis surface form a pattern of columnar pillars [18, 23, 32]. The apical parts of neighbouring surface cells are laterally separated by a channel network $\left([50,51]\right.$; Fig. $\left.1 C_{1}\right)$. In L. caerulea, the superficial epidermal cells are skewed such that the apical cell surface is positioned more distally than the basal one [34]. The outline of the apical epidermal cell surface in L. caerulea and several other species is exclusively polygonal, ranging from pentagonal to octagonal (e.g. [21, 22, 52]). In L. caerulea, Barnes et al. [21] found $65.4 \%$ hexagonal, $19.8 \%$ pentagonal, $14.2 \%$ heptagonal, and $0.6 \%$ octagonal, non-randomly distributed cells. 


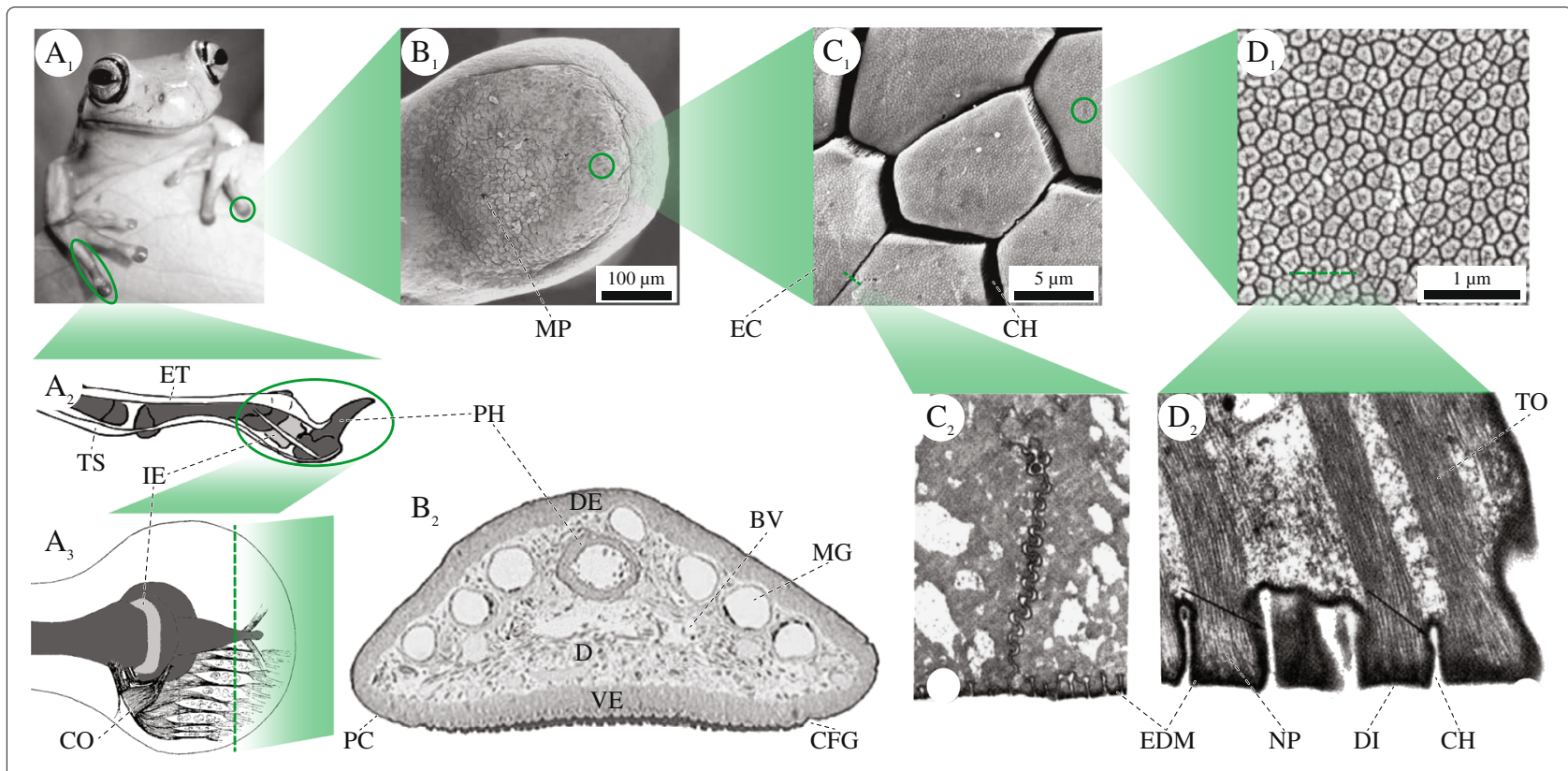

Fig. 1 Morphology of a digit and toe pad of a hylid tree frog. A Macroscopic structures. $\left(A_{1}\right)$ Forelimbs of Litoria caerulea. $\left(A_{2}\right)$ Schematic lateral view of tendons, phalangi (dark grey), and the intercalary element (light grey) in a digit of Scinax squalirostris. $\left(A_{3}\right)$ Schematic depiction of the collagen fibres in a pad of Hyla dominicensis in dorsal view. B Superficial and internal pad structures in L. caerulea. $\left(B_{1}\right)$ SEM image of the ventral epidermis. ( $\left.B_{2}\right)$ Transverse section through the toe of a juvenile frog. $\mathbf{C}$ Epidermal cells on the ventral surface. $\left(C_{1}\right)$ SEM image of polygonal cells in $L$. caerulea. $\left(C_{2}\right)$ TEM image of a tangential cross-section through the apical part of two adjacent cells in Hyla cinerea. D Fine structures of the apical surface of an epidermal cell. $\left(D_{1}\right)$ High power SEM image of nanopillars and their central depressions ('dimples') in L. caerulea. $\left(D_{2}\right)$ TEM image of a cross-section through a row of nanopillars in H. cinerea (black arrows: EDM). BV blood vessels, CFG circumferential groove, CH channel between two epidermal cells/nanopillars, CO collagen fibres, D dermis, DE dorsal epidermis, DI dimple, EC epidermal cell, EDM electron dense material, ET extensor brevis profundus tendon, IE intercalary element, MG mucus gland, MP mucus pore, NP nanopillar, PC pad curvature, PH (terminal) phalanx, TO tonofilaments, TS tendo superficialis, VE ventral epidermis. The illustrations are not to scale. $A_{1}, B_{1}, C_{1}$ and $D_{1}$ modified after [25]; $A_{2}$ modified after [66]; $A_{3}$ modified after [44]; $B_{2}$ modified after [47]; $C_{2}$ and $D_{1}$ modified after [23]. All figures printed with permission

Chen et al. [53] reported a similar distribution with 55\% of hexagonal cells, and an elongation of the cells along the proximal-distal pad-axis (aspect ratio $=1.46$ ) in Polypedates megacephalus. The apical cell surfaces are curved convexly $[25,50]$. In $H$. cinerea, the average edge length $a_{\mathrm{c}}$ of the apically separated cells is $10.2 \mu \mathrm{m}$ [23], the cell height $h_{\mathrm{c}}$ is $6.5 \mu \mathrm{m}$, and the apical cell surface $A_{\mathrm{c}}$ is $64 \mu \mathrm{m}^{2}$ [35]. Similar values for $A_{\mathrm{c}}\left(63-172 \mu \mathrm{m}^{2}\right)$ and cell diameter $d_{\mathrm{c}}(8-14.8 \mu \mathrm{m}$; see Fig. $2 \mathrm{~B})$ were reported for a number of species $[18,19,36,54,55])$. Smith et al. [42] found a positive correlation between $A_{\mathrm{c}}$ and $\ell_{\mathrm{SV}}(r=0.86 ; p=0.01$; 1-2 frogs per species), which was observed neither by McAllister \& Channing ([19]; 1-2 frogs per species) nor by Green ([54]; $r=0.036 ; 12-17$ frogs per species). Further work is required to conclude on the scaling of cell dimensions with $\ell_{\mathrm{SV}}$. The cell density $\rho_{\mathrm{c}}$ (cells per $\mathrm{mm}^{2}$ toe pad area) ranges between ca. 2450 and $15700 \mathrm{~mm}^{-2}$ $[35,42,56]$.

The channels in between the superficial epidermal cells are $1-5 \mu \mathrm{m}$ wide $[42,51]$. In P. megacephalus, the channel alignment is anisotropic; the cumulative channel length is ca. $70 \%$ lower along the lateral pad axis than along the proximal-distal axis [53]. Mucus glands with large lumina are distributed in the dermis of the distal digital segment (Fig. $1 \mathrm{~B}_{2} ;[51]$ ) and secrete mucus [57] via ducts and 7-8 $\mu \mathrm{m}$ wide pores into the epidermal channel network [58]. The spatial density and distribution pattern of the pores vary interspecifically $[18,19,36]$. A detailed analysis of the mucus gland morphology is unavailable.

Nanoscale Peg-like protrusions, called nanopillars (also plaques, pegs, or microvilli), cover the apical surface of the outermost epidermal cells ([33]; Fig. 1D $D_{1,2}$ ). Nanopillars are prismatic structures separated from each other by a nanoscopic channel network analogously to the microscopic channel network between the epidermal cells $[23,51]$. For various species, nanopillar diameters $\left(d_{\mathrm{n}}\right)$ of $15-800 \mathrm{~nm}$ were reported [18, 21-23, 37, 59]. In L. caerulea, the nanopillars have a (mostly) hexagonal outline with an aspect ratio of approximately 1 and a nanochannel width $w_{\mathrm{n}} \ll d_{\mathrm{n}}$ [22]. Measurement of $w_{n}$ by atomic force microscopy (AFM) presumably underestimates the channel width (and depth; [22]). AFM and transmission electron microscopy (TEM) measurements of the nanopillars $[23,25]$ and cryo-scanning electron 
microscopy (SEM; [21]) indicated a $7.7 \pm 4.2 \mathrm{~nm}$ deep 'dimple' on the apical surface (Fig. $\left.1 \mathrm{D}_{2} ;[22]\right)$.

Geometrical model of the epidermis Based on the dimensions of the epidermal cells reported in literature, we built a geometrical model (Fig. 2) of the epidermis to predict the increase in surface area by the cellular structures and the effective contact surface (that we assume to be formed by the apical nanopillar surfaces not covered by dimples). For calculations of the parameter values, see Additional file 1 .

For an approximately circular pad with diameter $d_{\mathrm{p}}=3.6 \mathrm{~mm}$, we compute a projected ventral area $A_{\mathrm{p}} \approx 10.2 \mathrm{~mm}^{2}$ covered with about $126 \cdot 10^{3}$ epidermal cells, which agrees with the cell densities reported for real animals [35, 42]. Cells with a regular hexagonal outline $\left(d_{\mathrm{c}}=10 \mu \mathrm{m}, h_{\mathrm{c}}=10 \mu \mathrm{m}, w_{\mathrm{c}}=1 \mu \mathrm{m}\right)$ increase the wetted contact area (i.e. the projected ventral surface + surface of the channel walls) 4.7-fold compared to a smooth pad. Nanopillars $\left(d_{\mathrm{n}}=300 \mathrm{~nm}, h_{\mathrm{n}}=300 \mathrm{~nm}\right.$, $w_{\mathrm{n}}=100 \mathrm{~nm}$ according to Fig. 3 in [21], dimple diameter $\approx d_{\mathrm{n}}-\Delta r=240 \mathrm{~nm}$ ) cover the apical surface of every cell. The whole pad contains ca. $73 \cdot 10^{6} \mathrm{n}$. This corresponds with a nanopillar density of ca. $7.1 \cdot 10^{6} \mathrm{~mm}^{-2}$, which is in the same order of magnitude as the setae densities reported in geckos [60]. Together, the epidermal cells and nanopillars enlarge the wetted contact area 6.6-fold compared to a smooth pad. About $20 \%$ of $A_{\mathrm{p}}$ is formed by the intercellular channel network. Including the nanoscopic channel network, this fraction rises to around 58\%. Dimples occupy $32 \%$ of the pad. Finally, about $10 \%$ of $A_{\mathrm{p}}$ is not covered by channels or dimples.

\section{Attachment control}

Several morphological elements in the limbs and digits of tree frogs are likely to contribute to an active control of attachment. The forelimbs are adapted towards an arboreal lifestyle. Specifically, kinematic and electromyographic analyses in L. caerulea and Phyllobates bicolor revealed that variations in the concerted action of the forelimb musculature allow for a power grip (i.e. clamping an object between flexed digits and palm), a precision grip (i.e. pinching an object between digit tips), and active positioning of the hands during climbing on narrow substrates [61]. A single layer of smooth muscle cells is present in the wall of each mucus gland [31,37]. This muscle type accommodates large strains and might enhance the deformability of the glands, minimising unintentional mucus secretion during pad loading. A dermal nerve plexus probably innervates the glandular muscle cells and thus controls mucus squeeze-out [51]. Several authors $[33,62,63]$ reported smooth muscle fibres in tree frogs' toe pads, which, however, was not confirmed in later literature [31, 37].

The mucus ducts are surrounded by several layers of tightly interconnected cells [31], which support the ducts mechanically and presumably facilitate mucus squeezeout. The dermal tissue between the terminal phalanx and the ventral epidermis is heavily vascularised (Fig. $1 \mathrm{~B}_{2}$; [44]), which might allow an active modification of pad curvature [64] and pad stiffness [47] by varying blood pressure.

\section{Force transmission}

The morphological basis of the transmission of attachment forces, generated at the pad-substrate interface, within the pad or to other body parts has not been studied extensively. An internal skeleton is the principle load bearing and transmitting structure in each limb (Fig. $1 \mathrm{~A}_{2,3}$ ). Many tree frog species have a cartilaginous intercalary element between the terminal and subterminal phalanx of each digit, which increases digit flexibility and facilitates

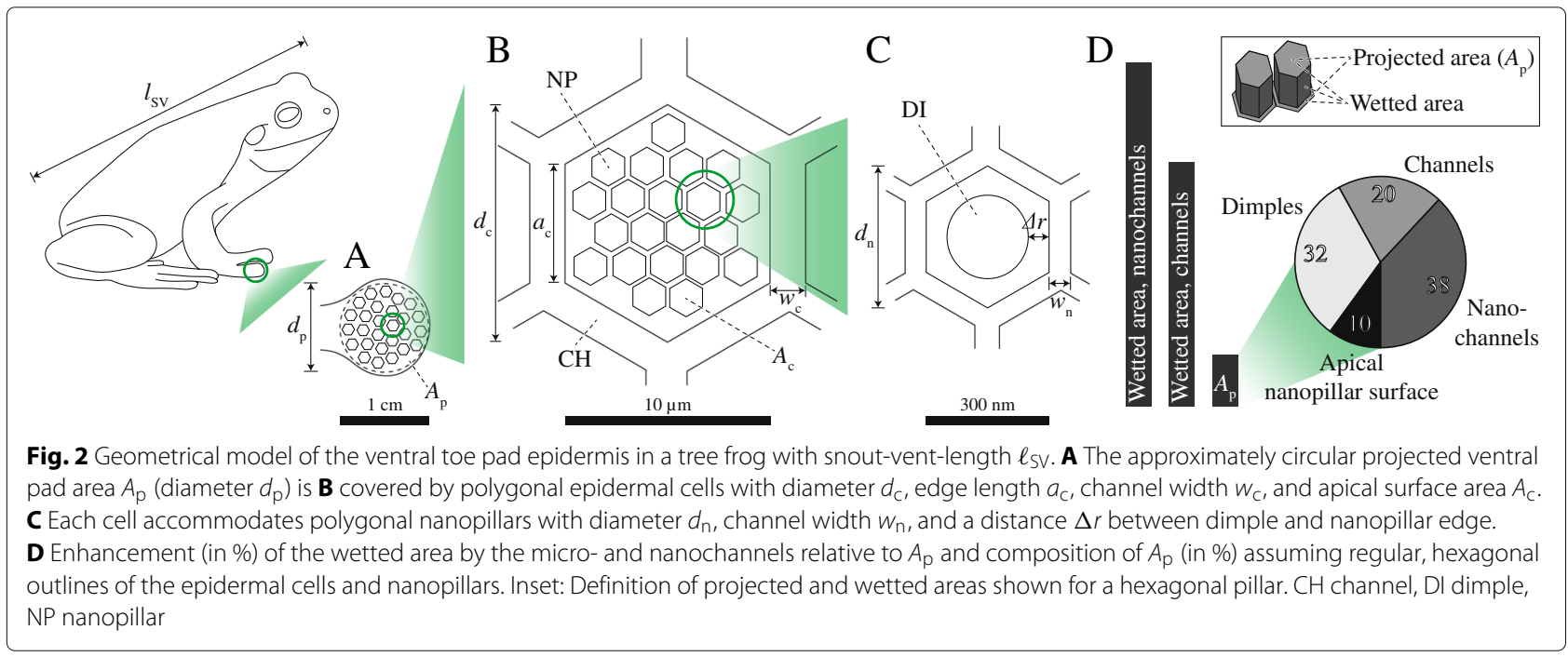


axial rotations of the terminal phalanx (Fig. $1 \mathrm{~A}_{2,3}$; e.g. $[6,65,66])$. In each digit, two tendons support the skeleton in load transmission: the dorsal Tendo Superficialis extends the digit, and a ventral tendon connected to the musculus extensor brevis profundus adducts the terminal phalanx (Fig. 1A $2 ;[6,66])$.

Collagen fibres connect the terminal phalanx with the ventral basement membrane $[44,62,65]$. The low lateral connectivity of the collagenous structures (Fig. $1 \mathrm{~A}_{3}$ ) suggests a low stiffness of the pad in dorso-ventral compression and lateral extension [31]. The deformable lymph space [34] and the blood-vessel network in the connective tissue also point towards low stiffness and viscoelastic properties of the pad.

The lateral membranes of adjacent epidermal surface cells are interconnected basally, which mechanically strengthens the epidermis (Fig. $1 C_{2} ;[23,37,51]$ ). Furthermore, tonofilament bundles-arranged parallel to the longitudinal axes of the superficial epidermal cells [52]-interconnect the cells through desmosomes [23, 31], split up towards the ventral surface, and terminate at the apical ends of the nanopillars (Fig. $1 D_{2}$; $[23,34,38,51])$. The ordered arrangement of the tonofilaments vanishes, as they extend into the deeper epidermal layers [23]. We expect that tonofilaments, collagenous structures, and digital bones together facilitate the transmission of attachment forces from the pad-substrate interface to the rest of the body (e.g. for locomotion). The local expression of keratins forming the tonofilaments in the nanopillars [67] supports the relevance of the tonofilaments for force transmission. A thin layer of electron dense material covers the inner side of the plasma membrane of the apical cells (Fig. $\left.1 D_{2} ;[23,51]\right)$.

\section{Material properties}

The high compliance of the toe pad in compression influences its attachment performance, for example by increasing the effective contact area on rough substrates. Compliance depends, among other properties, on the material-specific Young's modulus E, on the Poisson's ratio $v$, and on geometry and spatial arrangement of load- bearing structures. Overall, the toe pads were reported to be very soft [65], with an effective elastic modulus $E^{*}=E /\left(1-v^{2}\right)$ of the whole epidermis reported to be lower than that of most biological materials (e.g. [68]). Repeated indentation experiments showed no plastic deformation of the pad [22]. A small load-unload hysteresis in the force-displacement curve [22] and a decrease in the normal contact force during constant pad deformation [47] suggest viscoelasticity of the pad.

The effective elastic modulus of the toe pad varies by factors of up to $10^{4}$ between studies (Table 1). Such variations might be explained by the structure of the cytoskeleton [22], which makes $E^{*}$ strongly dependent on the location and direction of indentation, by the use of in vivo (e.g. [22]) versus ex vivo (e.g. [69]) samples, and by the use of different indenter shapes and contact mechanics models (e.g. Oliver-and-Pharr-theory in [22]; Johnson-Kendall-Roberts-/Hertz-model in other studies). Variations might also indicate a stiffness gradient [47] based on an increase of $E^{*}$ with indentation depth $d_{\mathrm{i}}$. The exact variation of $E^{*}$ with $d_{\mathrm{i}}$ is unknown.

\section{Mucus properties}

The mucus forms a liquid bridge with a meniscus that fully surrounds the toe pad [46] and has a wedge thickness of 5-10 $\mu \mathrm{m}$ [21]. The meniscus height and curvature are unknown. The mucus viscosity $\mu$ in $L$. caerulea is about $1.43 \mathrm{mPas}$, measured with laser-tweezer microrheometry [25]. The mucus is often approximated as a Newtonian liquid (i.e. $\mu$ is strain-rate-independent), but non-Newtonian liquid properties are suggested by the presence of polysaccharides in filled mucus glands in $H$. cinerea [31]. The static contact angle $\phi$ of mucus microdroplets on hydrophilic and hydrophobic substrates is low $\left(\phi \ll 10^{\circ}\right)$, which indicates an adhesive capillary function of the mucus independent of the wetting properties of the substrate [70].

\section{Functional demands on a toe pad}

Morphology and operation of an attachment organ are codetermined by the functional demands on the

Table 1 Experimental findings on the stiffness of tree frogs' toe pads

\begin{tabular}{|c|c|c|c|c|c|}
\hline Reference & Species & $\begin{array}{l}\text { Effective elastic modulus } E^{*} \\
{[\mathrm{kPa}]}\end{array}$ & $\begin{array}{l}d_{i} \\
{[\mu \mathrm{m}]}\end{array}$ & $\begin{array}{l}r_{\mathrm{i}} \\
{[\mu \mathrm{m}]}\end{array}$ & Remarks \\
\hline \multirow[t]{2}{*}{ [21] } & L. caerulea & $33.5 \pm 4.1$ & 0.2 & - & Ex vivo, AFM, Hertz theory \\
\hline & R. prominanus & $28.7 \pm 10.5$ & & & \\
\hline [22] & L. caerulea & 14000 & 1.6 & - & Pyramidal AFM tip \\
\hline [47] & L. caerulea & $4-25$ & 200 & - & Spherical MT, JKR-model \\
\hline \multirow[t]{2}{*}{ [69] } & L. caerulea & $54 \pm 7$ & 0.5 & 0.4 & Ex vivo, Spherical AFM, Hertz theory \\
\hline & & $40.7 \pm 3.2$ & & 13.3 & \\
\hline
\end{tabular}

$d_{\mathrm{i}}$ indentation depth, $r_{\mathrm{i}}$ indenter radius, AFM atomic force microscopy, JKR Johnson-Kendall-Roberts, MT microtribometry 
respective organ [15]. In the tree frog, these demands arise, among others, from the environment, phylogeny, and lifestyle of the animals.

\section{Directional contact forces}

Directional contact forces allow tree frogs to climb into the higher ecological layers of forests and other vegetation [71]. To stay attached to substrates with different inclination angles (e.g. overhanging leafs and vertical tree stems), tree frogs have to generate both strong adhesion and friction. The transmission of contact forces via skeletal elements suggests preferential directions of the contact force vector for whole limbs and single digits and thus anisotropic mechanisms of force generation. Gripping as a special case of force directionality is discussed elsewhere $[39,61,72,73]$.

\section{Substrates with diverse surface characteristics}

Tree frogs encounter a variety of substrates such as plant leaves, tree bark, insect cuticle, and stones, with a wide range of random or structured roughness $[68,74,75]$, surface energy (i.e. the energy required to form a unit area of free surface of a given material; [2]), stiffness [1], and wetting ${ }^{2}$ level. Natural substrates can be wetted via rain (e.g. in tropical habitats) and the mucus secretion on amphibian skin [72, 76, 77]. Environmental temperature, air humidity (e.g. [78]), and (mechanical or chemical) surface pollution may also affect the attachment performance of tree frogs. The ability of tree frogs to clean their pads by repeated stepping was discussed by Crawford et al. [71]. Generating contact forces that are high enough to keep the animals attached to natural substrates with different properties is arguably a primary demand on the toe pads.

\section{Static and dynamic attachment}

Tree frogs use a combination of locomotory modes such as jumping, horizontal walking, and vertical climbing [17], for which reversible and repeatable attachment is crucial [1]. For dynamic conditions, attachment and detachment (and switching between the two states; [79]) should be fast and controlled [80], and contact forces need to be large enough to resist detachment from the substrate during sudden events such as the attack of a predator or the wind-induced shaking of a leaf [81]. Additionally, toe pads enable static attachment, as observed in resting frogs $[13,33]$ or during copulation [76].

\section{Transmission of contact forces}

We expect toe pads to transmit the generated forces internally and to other body parts. Force transmission within a morphological unit, for example the epidermis, has been suggested to distribute mechanical stresses at the padsubstrate interface, hence reducing the risk of unwanted detachment [2] or of damaging the epidermis [15]. Force transmission between the epidermis and other body parts allows (directed) locomotion and requires a functional integration of the pads into the whole locomotory apparatus $([61,66]$; see also the functional morphology of force transmission), as observed in geckos [82].

\section{Basic theory of potential attachment mechanisms in a toe pad}

Various mechanisms of force generation [24], as well as lubrication [25] and drainage of the secreted mucus [83] have been suggested to play a role in the attachment and detachment of tree frogs. Here, we introduce these mechanisms for the subsequent discussion of their possible contributions to attachment. For a list of the used symbols and for a discussion of suction as potential adhesion mechanism, we refer to Additional file 1 .

\section{Force generation \\ Capillary forces}

A liquid bridge in the gap between the toe pad and the substrate can be formed by the secretion of mucus, by capillary condensation of water vapour, or by external surface wetting (e.g. rain droplets). The meniscus of this bridge can cause capillary contact forces (Fig. 3A), arising from the surface tension $\gamma$ of the liquid [84]. Capillary adhesion is attractive for a concave meniscus if seen from the gas phase (i.e. contact angle $\phi<90^{\circ}$ ); for water, a circular, concave meniscus is present on a hydrophilic substrate up to a

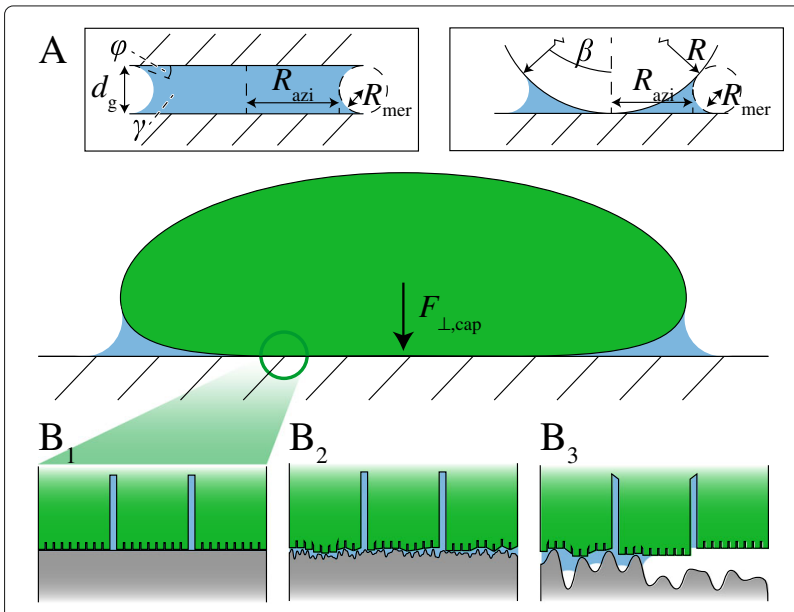

Fig. 3 A Schematic representation of capillary adhesion between a toe pad (green) and a hydrophilic substrate caused by the formation of a mucus meniscus (blue). Left inset: Capillary adhesion between two flat, solid plates. Right inset: Capillary adhesion between a solid sphere and a flat, solid plate. B Hypothesised changes in wetting state with an increase in substrate roughness or pad-substrate gap width [97]. $d_{\mathrm{g}}$ gap width, $F_{\perp, \text { cap }}$ capillary adhesion, $R$ sphere radius, $R_{\text {mer, }} R_{\text {azi }}$ meridional and azimuthal radius of meniscus curvature, $\beta$ filling angle, $\gamma$ mucus surface tension, $\phi$ contact angle. B modified after [97]. Printed with permission 
meniscus height $\kappa=(\gamma / g \rho)^{-0.5} \approx 2.7 \mathrm{~mm}(g$ gravitational acceleration, $\rho$ density).

A circular meniscus between two smooth, flat, rigid plates with equal contact angles (Fig. 3A, left inset) and with homogeneous surface energies is the first and most common model of capillary adhesion applied to tree frogs' toe pads (e.g. [24]). According to this model, the capillary adhesion $F_{\perp \text {,cap }}$ generated by a meniscus with azimuthal and meridional radii of curvature $R_{\mathrm{azi}}$ and $R_{\mathrm{mer}}$, respectively, is [2]:

$$
\begin{aligned}
F_{\perp, \mathrm{cap}} & =2 \pi R_{\mathrm{azi}} \gamma \sin \phi+\pi R_{\mathrm{azi}}^{2} \gamma\left(\frac{1}{R_{\mathrm{mer}}}-\frac{1}{R_{\mathrm{azi}}}\right) \\
R_{\mathrm{mer}} & =\frac{d_{\mathrm{g}}}{2 \cos \phi} .
\end{aligned}
$$

The first term represents the direct action of surface tension at the three-phase contact line (negligible at $\left.R_{\text {azi }} \ll R_{\text {mer }}\right)$, and the second term the effect of the Laplace pressure across the meniscus surface. In reality, the contact angle $\phi$ can differ strongly from the ideal case assumed in the described models, as a result of phenomena such as contact-line pinning, surface energy variations due to substrate roughness, or the entrapment of air between a rough substrate and a fluid meniscus (Fig. 3B; [85]).

The capillary adhesion between a rigid sphere (radius $R$ ) and a flat plate may represent tree frog attachment more closely than the plate-plate contact. For equal contact angles and a filling angle $\beta$ between the vertical and the three-phase contact line (Fig. 3A, right inset; [84]), Eq. 1 can be rewritten to model the sphere-plate contact:

$$
\begin{aligned}
F_{\perp, \mathrm{cap}}= & 2 \pi R \sin \beta \gamma \sin (\phi+\beta) \\
& +\pi R^{2} \sin ^{2} \beta \gamma\left(\frac{1}{R_{\mathrm{mer}}}-\frac{1}{R_{\mathrm{azi}}}\right) \\
R_{\mathrm{mer}}= & \frac{R(1-\cos \beta)}{2 c} \\
R_{\mathrm{azi}}= & R \sin \beta-R_{\mathrm{mer}}[1-\sin (\phi+\beta)] \\
c= & \frac{\cos (\phi+\beta)+\cos \phi}{2} .
\end{aligned}
$$

For $R \ll R_{\text {azi }} \ll R_{\text {mer }}$ and $\beta, \phi \approx 0$, Eq. 2 simplifies to:

$$
F_{\perp, \mathrm{cap}}=4 \pi R \gamma .
$$

The capillary adhesion between two deformable objects (one of them, for example, being a deformable sphere, which may represent a soft, round toe pad more closely than a rigid, flat plate) is stronger than between two rigid objects, because of an increased contact area in the former case [86, 87]. For a discussion on the capillary adhesion of deformable objects and on capillary friction we refer to Additional file 1.

\section{Hydrodynamic forces}

Mucus flow between toe pad and substrate during attachment and detachment generates hydrodynamic contact forces (Fig. 4). Hydrodynamic adhesion (also called Stefan or viscous adhesion) can be modelled assuming a flow between two flat, rigid plates with radius $r_{\mathrm{p}}$ fully immersed in a viscous liquid and initially separated by a distance $d_{\mathrm{g}}$ (Fig. 4A $\mathrm{A}_{2} ;$ [88]). During separation of the plates, liquid flows from the surroundings into the widening gap. Hydrodynamic adhesion $F_{\perp \text {,hyd }}$ is the force required to overcome the viscous resistance against this flow $[88,89]$ :

$$
F_{\perp, \text { hyd }}=-\frac{\partial d_{\mathrm{g}}}{\partial t} \frac{3}{2} \pi \mu \frac{r_{\mathrm{p}}{ }^{4}}{d_{\mathrm{g}}{ }^{3}} .
$$

Whereas the attachment of two plates may represent the contact of a flattened pad with a substrate reasonably well, we expect that a sphere-plate contact describes the approach of a submerged, curved pad to the substrate better. Between a smooth sphere with radius $R$ and a flat plate, $F_{\perp \text {,hyd }}$ is [90]:

$$
F_{\perp, \text { hyd }}=-\frac{\partial d_{\mathrm{g}}}{\partial t} 6 \pi \mu \frac{R^{2}}{d_{\mathrm{g}}} .
$$

Hydrodynamic forces act oppositely to the direction of surface movement and can hence also be repulsive. Hydrodynamic repulsion during the approach of deformable objects is lower, and adhesion during separation is higher than for rigid objects [91].

Next to adhesion and repulsion, hydrodynamic effects can also cause hydrodynamic (viscous) friction. For the shear flow of liquid between a stationary plate (i.e. the substrate) and a plate sliding at a speed $v_{\|}$parallel to the stationary one (i.e. the toe pad; Fig. $4 \mathrm{~B}_{2}$ ), the hydrodynamic friction $F_{\| \text {,hyd }}$ is [92]:

$$
\begin{aligned}
F_{\|, \text {hyd }} & =\mu A \frac{\partial u}{\partial y} \\
& =\mu A \frac{v_{\|}}{d_{\mathrm{g}}} .
\end{aligned}
$$

Equation 6 is only valid for gaps large enough to allow free shear flow (with a linear velocity profile), and the concept of hydrodynamic friction should be applied with caution to tree frogs' toe pads. It is likely that liquid is drained out of the pad-substrate gap during sliding, in which case Eq. 6 does not hold anymore, particularly with an increasing sliding distance. Alternatively, viscousporoelastic effects have been proposed to contribute to tree frog attachment [93].

\section{Van der Waals forces}

Van der Waals (vdW) interactions between single atoms or molecules of a toe pad and the substrate may cause adhesive and frictional contact forces (Fig. 5). VdW forces 

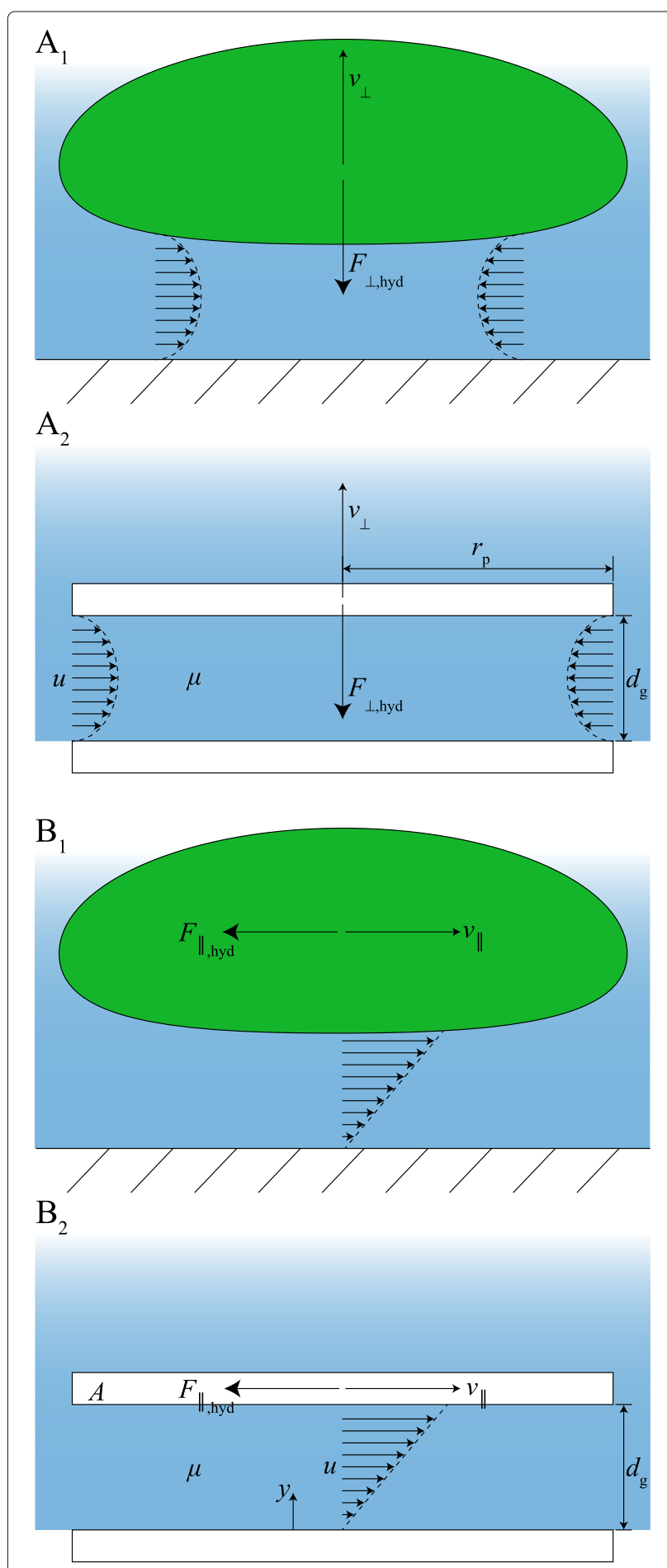

Fig. 4 Hydrodynamic (A) adhesion and (B) friction ( 1 ) during the schematic interaction between a toe pad (green) and the substrate based on displacement-induced flow of mucus (blue) and (2) in a model of the contact of two flat and rigid (cylindrical) plates. $A$ area, $d_{\mathrm{g}}$ gap width, $F_{\perp, \text { hyd }}$ hydrodynamic adhesion, $F_{\|, \text {hyd }}$ hydrodynamic friction, $r_{p}$ plate radius, $u$ flow speed, $v_{\perp}$ detachment speed, $v_{\|}$sliding speed, $y$ spatial coordinate normal to the substrate, $\mu$ viscosity are known to be dominant in the attachment of geckos (e.g. $[82,94])$ and might also play a significant role in tree frogs $[24,25]$. Between two flat plates with a contact area $A$ separated by a distance $d_{\mathrm{g}}$, the macroscopic vdW force $F_{\perp, \text { vdW }}$ is [95]:

$$
F_{\perp, \mathrm{vdW}}=-A \frac{A_{\mathrm{H}}}{6 \pi} \frac{1}{d_{\mathrm{g}}{ }^{3}}
$$

where $A_{\mathrm{H}}$ is the system-specific Hamaker constant. $A_{\mathrm{H}}$ scales with the electron density of the interacting molecules and with temperature [96].

Friction arising from vdW interactions between two objects sliding along each other is termed dry (or Coulomb) friction. Dry friction $F_{\|, \mathrm{vdW}}$ is proportional to the normal load $F_{\perp, \mathrm{L}}$ (i.e. a body weight component $F_{\perp, \mathrm{g}}$ and, if applicable, adhesion $F_{\perp}$ ) and the system-specific friction coefficient $\mu_{\|}$[96]:

$$
\begin{aligned}
F_{\|, \mathrm{vdW}} & =\mu_{\|} F_{\perp, \mathrm{L}} \\
& =\mu_{\|}\left(F_{\perp, \mathrm{g}}+F_{\perp}\right) .
\end{aligned}
$$

\section{Mechanical interlocking}

Mechanical interlocking is the mutual intermeshing of (parts of) an attachment organ and substrate asperities [3]. In tree frogs, interlocking between the epidermal cells and the asperities of a rough substrate has been proposed to contribute to attachment (Fig. 6; [24, 97]). Arguably, the attachment force generated by mechanical interlocking is proportional to the number of individual contact points.

\section{Liquid management}

The mucus between toe pad and substrate not only introduces hydrodynamic or capillary forces, it may also lubricate the pad during sliding and hinder closure of the pad-substrate gap requiring drainage of surplus mucus.

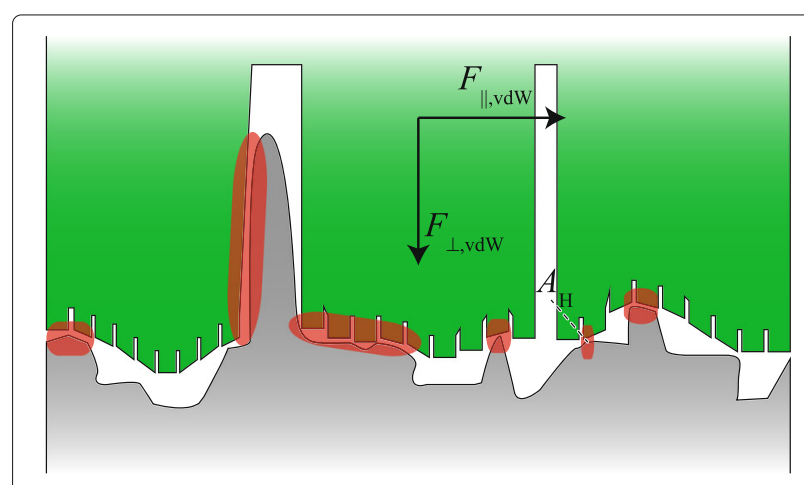

Fig. 5 Schematic generation of van der Waals (vdW) forces $\left(F_{\perp, v d W \text {, }}\right.$ $\left.F_{\|, v d W}\right)$ between ventral toe pad epidermis (green) and substrate (grey) for a system-specific Hamaker constant $A_{H}$. VdW interactions occur in regions of close pad-substrate contact (red) 


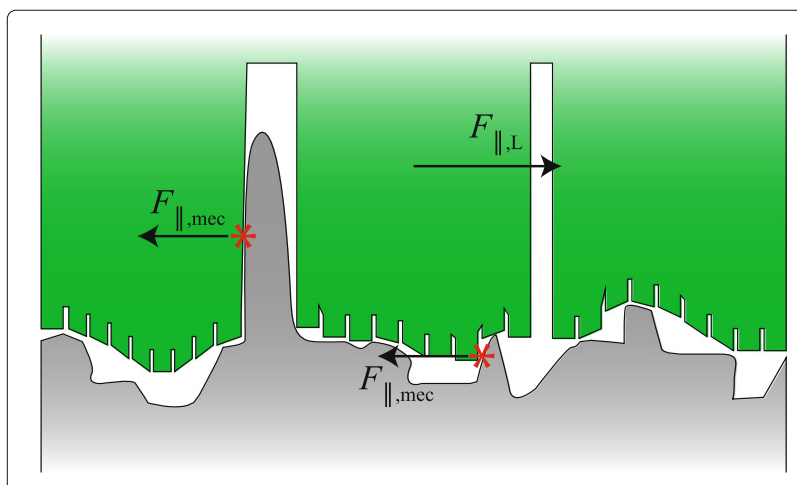

Fig. 6 Schematic mechanical interlocking between a superficial cell (left star) or a nanopillar (right star) on the ventral toe pad epidermis (green) and asperities of a rough substrate (grey) at a shear load $F_{\|, L}$

Here, we introduce the theories of lubrication and drainage with respect to their potential appearance in tree frog attachment.

\section{Lubrication}

Lubrication of an object sliding over a substrate with velocity $v_{\|}$changes the generated friction dramatically compared to dry friction (Fig. 7). The regime of lubrication of the pad-substrate-system depends on its Stribeck number St $=\left(\mu_{\|} v_{\|}\right) /\left(F_{\perp, \mathrm{L}} A^{-1}\right)$ [98]. At low St, dry padsubstrate contacts and dry friction dominate (boundary lubrication; Equation 8). At higher St (e.g. lower normal load $F_{\perp \text {,L }}$ per unit area), dry contacts between substrate asperities and the sliding toe pad become less frequent, and the load of the pad is carried both by dry contacts and enclosed volumes of mucus (mixed lubrication). At even higher St, the mucus carries most of the load, and the pad and substrate influence each other by deformation of substrate asperities through the mucus (elastohydrodynamic lubrication). At large St, loads are transmitted only via the mucus layer (hydrodynamic lubrication), and hydrodynamic friction occurs (Eq. 6).

\section{Drainage}

In artificial adhesives [99, 100], and possibly also in tree frogs, a channel network, which is separated by liquid from a substrate, leads to several drainage regimes depending on the gap width $d_{\mathrm{g}}$. In the nomenclature of these regimes, we follow Gupta \& Fréchette [99]. For $d_{\mathrm{g}} \gg d_{0}\left(=w_{\mathrm{c}}\left(h_{\mathrm{c}} /\left(w_{\mathrm{c}}+d_{\mathrm{c}}\right)\right)^{1 / 3} \approx 1 \mu \mathrm{m}\right.$ in tree frogs; $[99,100])$, radial squeeze-out of liquid through the gap (far field regime; Fig. 8A) was confirmed experimentally in artificial surfaces covered with cylindrical pillars [99]. For $d_{\mathrm{g}} \approx d_{0}$, liquid flows increasingly through the channels, which become the main source of hydrodynamic friction, down to a distance $d_{1}$ (intermediate field regime; Fig. 8B). For $d_{\mathrm{g}} \ll d_{0}$, the viscous resistance against liquid flow between single pillars and substrate dominates (near field regime; Fig. 8C). Drainage in tree frogs through the nanopillar channels and single nanopillar-substrate gaps may be assessed analogously to the drainage through microscopic artificial surface structures (Fig. 8D, E; [83]). In torrent frogs, the epidermal channel system is elongated along the proximal-distal pad axis [8, 11]. This elongation may ease the drainage of water flowing around the toe pads, hence enabling the strong attachment of these animals on overflowed substrates [8-12].

\section{Attachment performance of tree frogs}

The adhesive and frictional performance of tree frogs have been studied for whole animals and single limbs or toe pads. Adhesion and friction of whole frogs have been typically measured using a platform that rotates around a horizontal axis (Tables 2 and 3, top; Additional file 1: Figure SI.3), originally designed by Emerson \& Diehl [24] and refined by Hanna \& Barnes [6]. Simple trigonometry allows a calculation of adhesion and friction based on the measured inclination angles at which the animals slide on $\left(\alpha_{\|}\right)$and fall off $\left(\alpha_{\perp}\right)$ the platform (see Additional file 1). For single limb/pad-measurements, various force transducers (Tables 2 and 3, bottom) have been used. Effects of substrate properties on attachment forces have been also measured and behavioural traits related to attachment have been observed.

Here, we address findings on the attachment performance of tree frogs with respect to the questions stated in the introduction: Which mechanisms do contribute to tree frog attachment and how does the pad morphology support these mechanisms? We attempt to answer

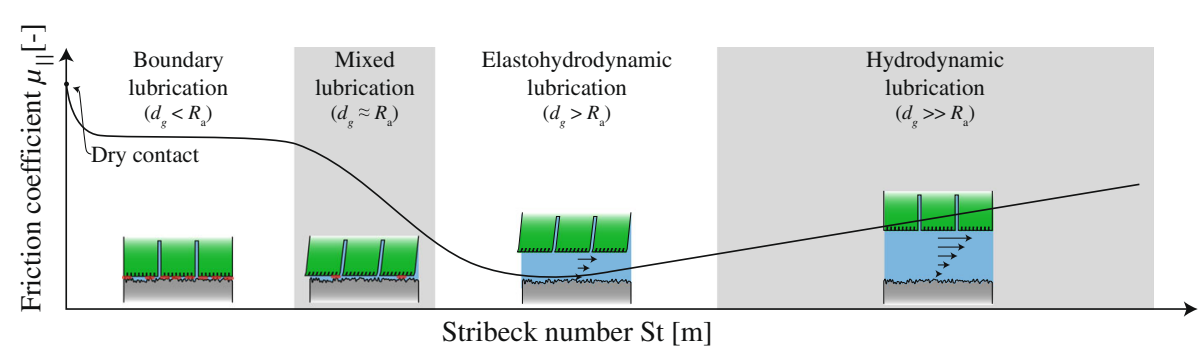

Fig. 7 Stribeck diagram showing the proposed spectrum of lubrication modes and the resulting friction coefficients $\mu_{\|}$in tree frogs' toe pads as a function of the Stribeck number St 


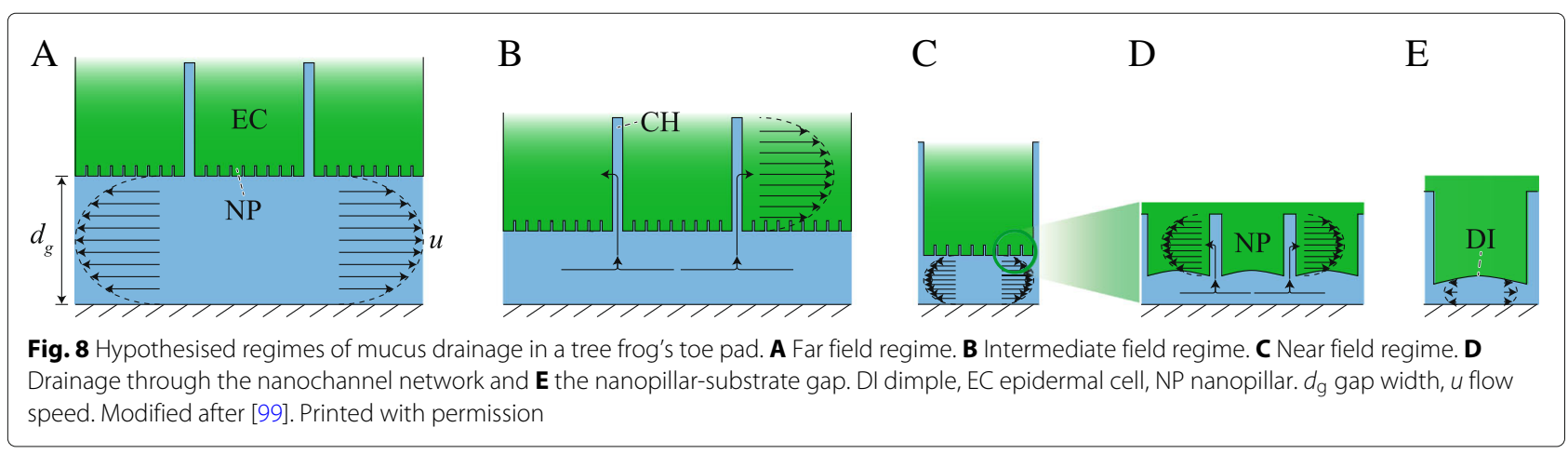

these questions by finding the best possible interpretation of the previous findings with regard to the pad properties, functional demands and, particularly, to the above described mechanisms, for example by comparison of measured contact forces with model predictions. Potential key questions and approaches for future developments in the field will be described in the final section.

\section{Adhesion}

Measured adhesion performance

Whole animals The adhesion measured for whole tree frogs ranges between 0.5 and $372 \mathrm{mN}$ (Table 2, top) and scales above squared with snout-vent-length $\ell_{\mathrm{SV}}$ $\left(F_{\perp} \propto \ell_{\mathrm{SV}}{ }^{2.19} ;[42]\right)$. Body mass $m$ scales roughly volumetrically (i.e. isometrically) with $\ell_{\mathrm{SV}}\left(m \propto \ell_{\mathrm{SV}}{ }^{3}\right)$, whereas the ventral pad area $A$ scales approximately quadratically with $\ell_{\mathrm{SV}}\left(A \otimes \ell_{\mathrm{SV}}^{2} ;[41]\right)$. The resulting negative scaling of contact area per body mass with body size [41, 42] leads to a decline in adhesive performance with body size [24, 40-43]. Adhesion scales as $F_{\perp} \propto A^{1-1.19}$ $[24,40,43]$ and at a higher rate with $\ell_{\mathrm{SV}}$ than $A$ [41], which is favourable compared to the situation of isometric scaling. For a discussion of potential adaptations to the problem of isometric scaling, see Smith et al. [42].

Despite a variation of the measured adhesion by a factor of $10^{4}$, the tenacity (i.e. adhesive force per unit area) measured for whole tree frogs on smooth substrates varies relatively little, between 0.3 and $1.4 \mathrm{mN} \mathrm{mm}^{-2}$ (Table 2 , top). In these calculations, however, contact area was assumed to equal the total ventral area of all toe pads (e.g. $[6,41]$ ), whereas during the actual rotating platform experiments the frogs tend to change the number and size

Table 2 Measured adhesion performance of whole tree frogs (top) and of single limbs/toe pads (bottom; SP unless stated otherwise) on smooth dry substrates

\begin{tabular}{lllll}
\hline Reference & Species & $\begin{array}{l}\text { Adhesion } F_{\perp} \\
{[\mathrm{mN}]}\end{array}$ & $\begin{array}{l}\text { Tenacity } \sigma_{\perp} \\
{\left[\mathrm{mN} \mathrm{mm} \mathrm{mm}^{-2}\right]}\end{array}$ & Remarks \\
\hline$[6]$ & O. septentrionalis & 75.5 & 1.2 & PMMA \\
{$[24]$} & H. cinerea & 39.24 & 1.4 & Teflon \\
{$[40]$} & various hylids & $2.0-372.0$ & $0.4-1.3$ & PMMA \\
{$[41]$} & various hylids & $4.3-180.2$ & $0.4-0.7$ & PMMA \\
{$[42]$} & various hylids & $0.5-200.0$ & $0.30-1.08$ & PMMA \\
{$[71]$} & L. caerulea & $255.3 \pm 73.7$ & - & Glass \\
{$[6]$} & O. septentrionalis & $5.9 \pm 2.1-14.9 \pm 3.6$ & - & SL \\
{$[10]$} & R. pardalis & - & 1.5 & PE \\
{$[39]$} & R. dennysi & $1.7-11.3$ & $1.1-2.3$ & SL, Frontlimb, Metal \\
{$[65]$} & H. arborea & 127.53 & - & Glass \\
{$[71]$} & L.caerulea & - & $1.08 \pm 0.24$ & Resin \\
{$[97]$} & L. caerulea & - & $1.74 \pm 1.90$ & PDMS
\end{tabular}


of pad contacts. Therefore, the maximum tenacity is presumably underestimated, and accordingly the goodness of fit of the interspecific tenacity scaling by Smith et al. [42] with body size $(r=0.78, p=0.04)$ and epidermal cell size is low $(r=0.81-0.92, p=0.003-0.02$, min. 1 animal for $A_{\mathrm{p}}$, min. 10 animals for $F_{\perp}$ ). Furthermore, a significant intraspecific correlation of $\sigma_{\perp}$ with $\ell_{\mathrm{SV}}$ is not found in all tree frog species [41].

Single limbs/pads Tenacities measured in single pads agree with whole animal tenacities (Table 2, bottom). Endlein et al. [39] reported an effect of the detachment kinematics on tenacity: proximal pulling on the pads before detachment led to higher tenacities compared to detachment in a dabbing movement. Similarly, Barnes et al. [101] measured in L. caerulea a negative scaling of the tenacity with the pull off angle $\theta_{\mathrm{L}}$ between substrate and pulling force from $1.12 \mathrm{mN} \mathrm{mm}^{-2}$ at $53^{\circ}$ to $0.04 \mathrm{mN} \mathrm{mm}^{-2}$ at $170^{\circ}$, pointing towards peeling of the toe pads.

Local indentations In adult $L$. caerulea, Barnes et al. [47] measured normal pull-off forces (i.e. adhesion) of $585-609 \mu \mathrm{N}$ using a spherical indenter with radius $r_{\mathrm{i}}=1.5 \mathrm{~mm}$ at indentation depths $d_{\mathrm{i}} \approx 50-350 \mu \mathrm{m}$. Assuming a surface area $A=2 \pi d_{\mathrm{i}} r_{\mathrm{i}}$ for the spherical cap of the indenter in contact with the pad, we computed tenacities of $0.17-1.29 \mathrm{mN} \mathrm{mm}^{-2}$, which overlaps with the values reported above. Similarly, Kappl et al. [69] measured adhesion of $5 \mathrm{nN}$ in dead L. caerulea using a spherical AFM-indenter $\left(r_{\mathrm{i}}=13.3 \mu \mathrm{m}\right)$ at $d_{\mathrm{i}} \approx 250-300 \mathrm{~nm}$ for submerged pads (i.e. no capillary force generation), from which we calculated tenacities of $0.12-0.24 \mathrm{mN} \mathrm{mm}^{-2}$.

\section{Adhesion mechanisms}

Capillary adhesion Tree frog adhesion has been attributed primarily to wet adhesion considering that: (i) Mucus fills the pad-substrate gap and forms a capillary meniscus [24]. (ii) Nachtigall [102] measured for two glass plates separated by distilled water a capillary tenacity of $7 \mathrm{mN} \mathrm{mm}^{-2}$, which is in the same order of magnitude as tenacities measured for tree frogs. (iii) Tree frog adhesion scales linearly with $A$, as predicted by capillary adhesion based on Laplace pressure (Eq. 1; [24]), assuming a size-invariant meridional meniscus curvature. (iv) On rough substrates, adding liquid improves the adhesive performance, proposedly by sustaining the meniscus.

To theoretically investigate the role of capillary adhesion, we calculated the capillary tenacity for various combinations of meniscus curvatures (i.e. meniscus height and pad diameter). Since the adhesion between a sphere and a plate (Eq. 3) does not show the area-scaling measured in tree frogs $[24,40,43]$, we modelled the padsubstrate interaction as plate-plate contact (Eq. 1). As shown in Fig. 9, a meridional radius of meniscus curvature $R_{\mathrm{mer}}$ similar in size to the micro- to nanoscopic height $d_{\mathrm{g}}$ of the mucus film (e.g. $5 \mu \mathrm{m}$ estimated in [40]) would lead to capillary adhesion that is several orders of magnitude higher than the tenacities measured in tree frogs. In reality, the meniscus covers also the side of the pad [21] and therefore $R_{\text {mer }} \gg d_{\mathrm{g}} / 2$ (compare Fig. 3A, left inset). Thus, Eq. 1 might well describe tree frog adhesion under the assumption of a realistic radius of meniscus curvature that is much larger than the narrow pad-substrate gap width. Based on Fig. 9, we predict $R_{\mathrm{mer}} \approx 150 \mu \mathrm{m}$. As discussed by Drechsler \& Federle [103], we would expect a minimisation of the radii of meniscus curvature (i.e. just enough mucus to fill the pad-substrate gap as found in artificial structured adhesives [70]) in pads adapted towards capillary adhesion.

Figure 9 further shows that, depending on pad size, both meniscus curvatures have to considered in computing the capillary adhesion of tree frogs' toe pads. To our knowledge, models of the capillary adhesion of tree frogs, such as the ones discussed above or in previous works (e.g. $[6,7,24,104])$, do not take into account variations in the contact angle (and hence of meniscus curvature) related to wetting phenomena such as contact-line pinning or substrate roughness [85].

The linear scaling of adhesion with contact area [41] is not only explained by capillary adhesion. For example, such scaling might also originate from suction,

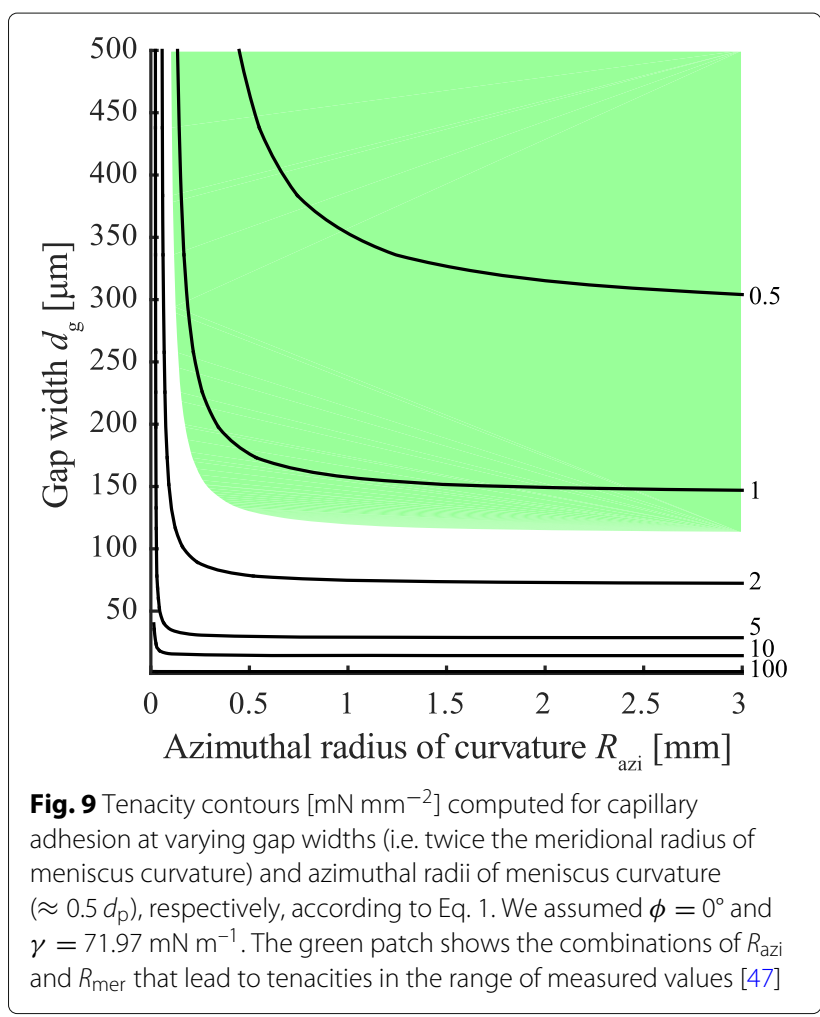


mechanical interlocking, or vdW forces, assuming a uniform load-distribution over the contact area. In contrast to capillary effects, the latter two mechanisms might directly explain the friction of tree frogs' toe pads.

With respect to morphology, the micro- to nanoscopic channel system has been suggested to support capillary adhesion by quickly spreading the mucus over the pad surface for a rapid formation of the liquid bridge $[9,83]$. In addition, the channels may facilitate the capillary condensation of water vapour into the pad-substrate gap, reducing the need to actively secrete mucus. However, the distance at which a capillary bridge forms between substrate and an artificial adhesive covered with a channel network is reduced, presumably because liquid is redistributed from the liquid bridge into the channels [70]. Accordingly, channels could also counteract quick generation of capillary adhesion, particularly if there is only little liquid present in the pad-substrate gap.

Hydrodynamic adhesion Hydrodynamic models predict an above-area scaling of adhesion with $\ell_{\mathrm{SV}}$, which disagrees with the area-scaling measured in tree frogs. Therefore, viscosity-based forces are not believed to play an important role in tree frog adhesion [6, 24]. Due to its inherent rate-dependency, hydrodynamic adhesion might prevent rapid detachment [41], which would inhibit, for example, jumping. Other adhesive mechanisms such as capillary adhesion or vdW forces do not show such an inherent rate-dependency [105]. Furthermore, hydrodynamic adhesion requires continuous pad movements, rendering this mechanism ineffective against continuous forces such as gravity. For a deformable pad, gap closure (and hence the formation of potential dry contacts or of low gap widths for strong hydrodynamic adhesion) presumably is even slower compared to a rigid one [91]. In other words, hydrodynamic adhesion seems more of a hindrance for the animal (i.e. attachment and detachment are retarded and adaptations towards control of hydrodynamic forces may be needed), rather than a primary mechanism of adhesion.

The empirical and modelling evidence of hydrodynamic adhesion in the soft and patterned toe pads of tree frogs is limited. Current analytical models assume the contact of rigid objects. With decreasing stiffness, fluid-structure interactions increasingly affect hydrodynamic adhesion [91], and contact forces resulting from viscoelastic substrate deformations can even exceed the hydrodynamic forces [106]. Moreover, current models assume smooth surfaces. Modified hydrodynamic boundary conditions are needed to model flow over structured surfaces [107]. Further work is required to examine if current analytical models of hydrodynamic adhesion can represent tree frog attachment accurately.
Van der Waals forces Previously, large gap widths and a decrease of $A_{\mathrm{H}}$ as a result of the liquid present in the pad-substrate gap were stated to prevent any significant contribution of vdW forces in tree frog attachment [24]. To examine the possibility of $\mathrm{vdW}$ forces in tree frogs, we calculated the vdW-tenacity using Eq. 7 for various combinations of pad-substrate gap width $d_{\mathrm{g}}$ and Hamaker constant $A_{\mathrm{H}}$ for a range of values expected for tree frogs' toe pads (Fig. 10; max. $A_{\mathrm{H}} \approx 10^{-19} \mathrm{~J}$ in dry conditions [96]; min. $A_{\mathrm{H}} \geq 0.7 k_{\mathrm{b}} T=2.9 \cdot 10^{-21} \mathrm{~J}$ for water between two similar materials at temperature $\mathrm{T}=26^{\circ}$ and Boltzmann constant $k_{\mathrm{b}}=1.4 \cdot 10^{-23} \mathrm{~J} \mathrm{~K}^{-1}$ ). Even in a conservative prediction using $A_{\mathrm{H}}=2.9 \cdot 10^{-21} \mathrm{~J}$ and an effective contact area of $10 \%$ of $A$, this model yields vdW tenacities equal to or higher than $1 \mathrm{mN} \mathrm{mm}^{-2}$ (see Additional file 1) at $d_{\mathrm{g}} \leq 2.5 \mathrm{~nm}$ on a smooth substrate. For a 10 fold higher Hamaker constant, which is in the range of values reported for two dissimilar organic objects interacting across water $[96,105]$, vdW forces are equal to or higher than the adhesion measured in tree frogs at $d_{\mathrm{g}} \leq 6.7 \mathrm{~nm}$. Using interference reflection microscopy, Federle et al. [25] measured $d_{\mathrm{g}} \leq 5 \mathrm{~nm}$ for more than $40 \%$ (and $d_{\mathrm{g}} \leq 10 \mathrm{~nm}$ for more than $55 \%$ ) of the analysed epidermal cells. This sensitivity analysis suggests that tree

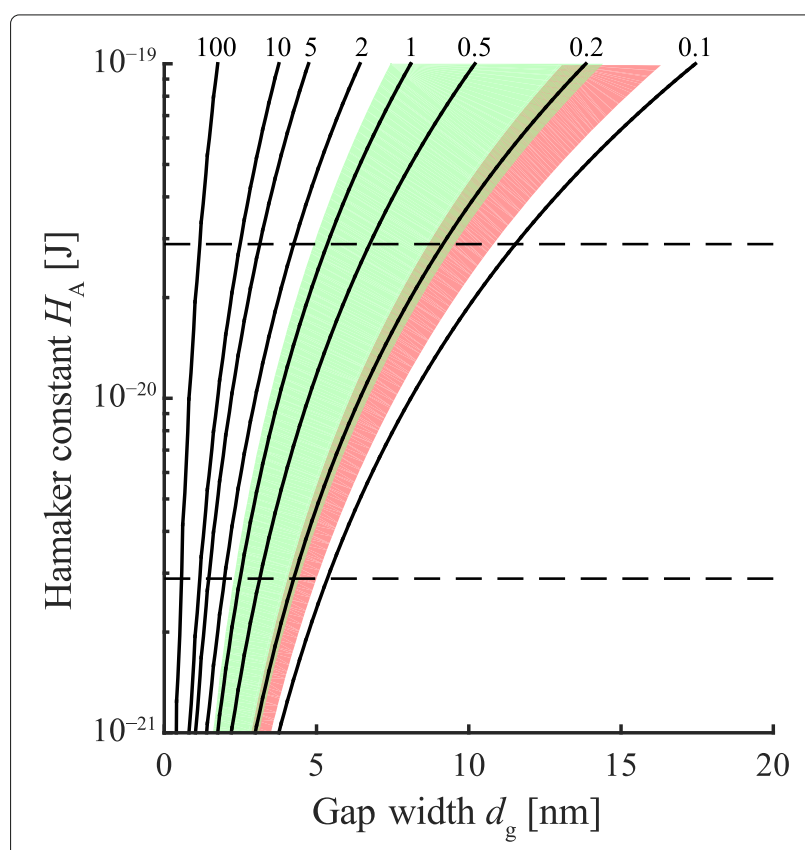

Fig. 10 Tenacity contours $\left[\mathrm{mN} \mathrm{mm}^{-2}\right]$ computed for van der Waals ( $v d W$ ) interactions at various Hamaker constants and gap widths according to Equation 7 . We assumed that $10 \%$ of the contact area contributes to vdW force generation. Dashed lines: Theoretical minimum Hamaker constant for water separating two similar materials at $26^{\circ} \mathrm{C}$ (bottom) and a 10 -fold higher Hamaker constant (top). Coloured patches show the combinations of $A_{H}$ and $d_{\mathrm{g}}$ leading to tenacities in the range of measured values ([47], green; [69], red) 
frogs are potentially able to conform close enough to the substrate to generate significant $\mathrm{vdW}$ forces despite liquid in the pad-substrate gap and a reduced Hamaker constant.

Morphological observations also support the action of $\mathrm{vdW}$ forces in toe pads. The accumulation of electron dense material in the outermost layer of the nanopillars (Fig. 1D $\mathrm{D}_{2}$ ) could increase vdW interactions [105], analogously to the effects of varying thicknesses of the substrate backing material on the vdW forces reported for geckos [94].

Summarizing, the contribution of vdW forces to adhesion cannot be excluded in tree frogs (although more experimental evaluation is needed). Quantifications of the Hamaker constant, the pad-substrate gap width, and the attachment performance on substrates with different surface energies or with chemically different backing layers (as performed for geckos in [94]) are required for a detailed assessment of the contribution of vdW forces to tree frog attachment.

Drainage Most mechanisms described in this review predict an increase in adhesion (and friction) with decreasing pad-substrate gap width. Liquid in the padsubstrate gap impedes a close conformation of the pad, and adaptations towards liquid drainage might be at play. The different drainage regimes could help explain the function of the micro- to nanoscopic channel network in between the ventral epidermal cells and nanopillars. These channels might effectively enlarge the gap width [83], and reduce hydrodynamic repulsion (Eqs. 4 and 5). Thus, drainage would alleviate a reduction of the gap width and reduce the duration of contact formation (and separation). The grip to the substrate would be closer and faster, as demonstrated for artificial surface structures $[53,70,99,100]$. As described above, the flow through the channel network is dominated by viscous effects $[99,100]$.

\section{Friction \\ Measured friction performance}

Table 3 summarizes the friction $F_{\|}$and shear stress $\sigma_{\|}$ measured for whole tree frogs and single limbs/toe pads. Static friction exceeds adhesion in terms of force [9] and stress $[39,97]$. The static friction coefficient $\mu_{\|}$of a pad ranges between 0.77 and 1.98 in various species tested on PMMA [9, 40]. For single toe pads, Chen et al. [53] measured that friction during sliding along the longitudinal pad axis exceeds the friction of lateral sliding by ca. 20\%. Kappl et al. [69] reported a contradictory trend of 29-71\% higher friction coefficients for lateral sliding of single epidermal cells. Friction scales with $\ell_{\mathrm{SV}}$ just below cubed $\left(F_{\|} \propto \ell_{\mathrm{SV}}{ }^{2.76-2.78} ;[9,40]\right)$, indicating an approximately linear scaling with body mass. Federle et al. [25] measured a static shear stress of $1.12 \mathrm{mN} \mathrm{mm}^{-2}$ two minutes after the end of sliding, which was explained by boundary lubrication (i.e. dry friction).

Friction dynamics are hardly studied in tree frogs. Single pad friction scales positively with sliding velocity in Osteopilus septentrionalis [6]. In L. caerulea, a (median) dynamic shear stress of $2.1 \mathrm{mN} \mathrm{mm}^{-2}$ was reported [25]. Dynamic peak friction values of up to $1270 \mathrm{mN}$, equivalent to 14.4 times the body weight, were reported for single pads of Trachycephalus resinifictrix [80]. We expect that

Table 3 Measured friction performance of whole tree frogs (top) and of single limbs/toe pads (bottom; SP unless stated otherwise). For explanation of abbreviations see Table 2

\begin{tabular}{|c|c|c|c|c|c|c|}
\hline Reference & Species & $\begin{array}{l}\text { Friction } F_{\|} \\
{[\mathrm{mN}]}\end{array}$ & $\begin{array}{l}\text { Shear stress } \sigma_{\|} \\
{\left[\mathrm{mN} \mathrm{mm}^{-2}\right]}\end{array}$ & $\begin{array}{l}F_{\perp, L} \\
{[\mathrm{mN}]}\end{array}$ & $\begin{array}{l}v_{\|} \\
{\left[\mu \mathrm{m} \mathrm{s}^{-1}\right]}\end{array}$ & Remarks \\
\hline [40] & various hylids & $5.5-585.7$ & - & - & - & PMMA \\
\hline [71] & L. caerulea & $285.4 \pm 94.5$ & - & - & - & Glass \\
\hline \multirow[t]{2}{*}{ [6] } & \multirow[t]{2}{*}{ O. septentrionalis } & $24.9 \pm 6.6-55.4 \pm 6.3$ & - & - & - & \multirow[t]{2}{*}{ SL } \\
\hline & & $3.0-130.3$ & - & 2.5 & $10-2500$ & \\
\hline [10] & R. pardalis & - & 1.5 & - & - & Glass \\
\hline [25] & L. caerulea & - & $1.08-2.01$ & 0.1 & 500 & Glass \\
\hline [39] & R. dennysi & $25.1-51.2$ & 9.6 & 2 & 600 & Varying detachment kinematics \\
\hline [46] & H. versicolor & 357.1 & - & - & - & Pulling experiment, Frontlimbs \\
\hline [53] & P. megacephalus & 17.52 & - & 3 & 300 & Glass \\
\hline [80] & T. resinifictrix & $110-1270$ & - & - & - & Jumping kinematics, Wood; SL \\
\hline \multirow[t]{2}{*}{ [97] } & \multirow[t]{2}{*}{ L. caerulea } & - & $7.8 \pm 12.9$ & \multirow[t]{2}{*}{2} & \multirow[t]{2}{*}{1000} & Resin \\
\hline & & - & $5.9 \pm 2.6$ & & & PDMS \\
\hline [113] & L. caerulea & $1.6-10.4$ & - & - & - & SL \\
\hline [112] & P. megacephalus & $14.5-122.7$ & - & - & - & Repeated sliding \\
\hline
\end{tabular}

$F_{\perp, L}$ normal load, $v_{\|}$sliding speed 
the high frictional performance reported in recent studies $[39,53,80,97]$ can be explained by a scaling of friction with normal load and shear velocity.

\section{Friction mechanisms}

Mechanical interlocking Interlocking of epidermal cells or nanopillars with substrate asperities might contribute to friction (and adhesion) of tree frogs [46]. Interlocking might explain the enhanced attachment forces measured on substrates covered with artificial pillars similar in size to the epidermal cells (and channels; [97]). An enhanced contact area for dry or hydrodynamic friction might be an alternative explanation of this observation.

Overall, interlocking, as described for stiffer attachment organs such as claws $[108,109]$, is debatable for the delicate epidermal cells of tree frogs. The use of substrates with a well-defined topography (e.g. structured or random roughness as in [97]) is crucial in future investigations.

Lubrication: from dry to hydrodynamic friction The measured mass- (and therefore load-) scaling of friction [40], the observation of static friction, and nanoscopic pad-substrate gap widths [25] indicate the presence of dry friction. However, the measurement of a lower static than dynamic friction [25] conflicts with dry friction and suggests the action of additional friction mechanisms.

For example, the presence of mucus and the positive scaling of friction with sliding velocity point towards hydrodynamic friction (or possibly rubber friction; $[9,95])$. Physiological adaptations towards enhanced hydrodynamic friction could target the mucus viscosity, velocity gradients, and contact area: the wetted contact area, which is considerably larger than the projected area, and high velocity gradients because of the nanoscopic pad-substrate distances may enhance hydrodynamic friction, despite a low mucus viscosity.

Overall, we expect that tree frogs experience the whole lubrication spectrum from dry to hydrodynamic friction, with boundary lubrication as preferred regime of lubrication, because it provides static friction, which is load-dependent and hence controllable.

Lubrication might also explain the large amount of glands secreting mucus into the pad-substrate gap. Compared to geckos [82], the surface of tree frogs' toe pads is keratinised only little and is accordingly very soft. While this facilitates the uptake of water and oxygen through the skin [110] and enhances the substrate conformability, we also expect the soft pads to be more susceptible to abrasive wear [95]. A thin layer of mucus (i.e. a few layers of mucus molecules) might act as lubricant to avoid excessive damage of the pad epidermis while maintaining a sufficiently high pad friction.
Friction anisotropy Lubrication could also cause the anisotropic friction of polygonal surface structures observed in toe pads [53], with a higher friction in the longitudinal direction than in the lateral direction, and in artificial surfaces [12], where the friction of a regular pattern of regular hexagonal pillars is $60^{\circ}$-symmetric: friction anisotropy might arise from direction-dependent liquid flow in the channel network because of anisotropic channel alignment [53], or from the anisotropic geometry and bending stiffness of the surface structures [12]. Furthermore, we propose that the anisotropic channel alignment could lead to anisotropic sliding velocities and a direction-dependent transition to another lubrication regime (and friction coefficient). In tree frogs, high friction along the proximal-distal pad axis seems most important, as suggested by yawing motions of the toe pads in jumping frogs before landing [80], which agrees with anisotropic friction predicted by the theories of anisotropic flow.

\section{Effects of variations in substrate properties on attachment} Measured effects

Roughness In Fig. 11, we provide an overview of tree frog adhesion as a function of the (arithmetic) average roughness $R_{\mathrm{a}}$ of the substrate. For $R_{\mathrm{a}}<6 \mu \mathrm{m}$, the tenacity was reported to increase compared to a smooth surface [97]. Crawford et al. [97] also measured a higher tenacity on a substrate with structured roughness (i.e. $3 \mu \mathrm{m}$ high and $2 \mu \mathrm{m}$ wide pillars with variable spacing) than on a smooth substrate. With increasing pillar spacing, the tenacity returns to the values measured for smooth substrates at a spacing $\geq 10 \mu \mathrm{m}$. Tree frogs tend to adhere worse to rough substrates [43], for example wood or coarse sandpaper, which was also observed for smooth substrates contaminated with glass beads with a diameter of $50 \mu \mathrm{m}$ [71]. At $R_{\mathrm{a}} \geq 0.5 \mathrm{~mm}$, adhesion increases again.

Effects of $R_{\mathrm{a}}$ on friction have been hardly studied. Compared to various other substrates, in ten species the highest friction coefficients were found on wood [9]. Similar to adhesion, higher shear stresses were measured on substrates with $R_{\mathrm{a}}=3-6 \mu \mathrm{m}$ than on smoother substrates [97]. For microscopic glass beads (diameter $<3 \mu \mathrm{m}$ ), Crawford et al. [97] observed interlocking of the beads in the intercellular epidermal channels.

Wetting Tree frogs cannot attach to a fully wetted, smooth substrate [13, 24, 65, 111]. Endlein et al. [10] described a reduction of $\sigma_{\perp}$ from ca. $1.5 \mathrm{mN} \mathrm{mm}^{-2}$ to ca. $0.1 \mathrm{mN} \mathrm{mm}^{-2}$ when wetting the pad with $10 \mu \mathrm{L}$ of water, which is equivalent to a $2.3 \mathrm{~mm}$ thick liquid film assuming an average pad surface of $4.3 \mathrm{~mm}^{2}$. On rough substrates, on the other hand, light wetting (i.e. rates of $0.8-1.9 \mathrm{~mL} \mathrm{~s}^{-1}$ of water flowing over the test substrate or spraying water on the substrate) increases adhesion 
compared to dry conditions [9, 10, 43, 97]. Crawford et al. [97] reported the ability of $L$. caerulea to fill gapscreated by $50-75 \mu \mathrm{m}$ large glass beads contaminating the substrate-with mucus. For even larger beads, air bubbles formed in the pad-substrate gap.

'Full' wetting weakens friction on smooth and rough substrates [10]. In repeated friction measurements on individual toe pads (10 consecutive steps), Zhang et al. [112] measured an increase of friction with step number (from $14.5 \mathrm{mN}$ to $122.7 \mathrm{mN}$ ), presumably because of a reduction of the liquid volume between pad and substrate. Similar to adhesion, friction on a rough substrate $(58.5 \mu \mathrm{m})$ increases by light wetting [97].

Surface energy/tension The only study investigating the influence of substrate surface energy on adhesion reported a difference of the mean falling angle by $9^{\circ}$ in frogs sitting on glass versus teflon [24]. A reduction in surface tension of the intervening liquid by wetting a substrate with water mixed with a detergent led to a complete loss of friction [46].

\section{Functional interpretation of measured effects}

Capillary adhesion The reduced adhesion of tree frogs on dry, rough substrates has been attributed to the formation of bubbles within substrate cavities (Fig. 3B 3 ), reducing the contact area available for capillary adhesion [43]. However, meniscus cavitation around glass beads in the pad-substrate gap occurs only for bead diameters $>50 \mu \mathrm{m}$ [97], leaving the reduced adhesion at lower roughnesses unexplained by reduced capillary forces. In addition, capillary adhesion is unlikely to explain the increased adhesion on rough substrates for $R_{\mathrm{a}} \leq 6 \mu \mathrm{m}$ [97], unless the low contact angle is further reduced because of roughness. These observations point towards the action of other adhesion mechanisms that are affected by microscopic roughness levels.

The loss of adhesion on a fully wetted substrate may result from a complete destruction of the meniscus and of capillary force generation [24]. Alternatively, strong wetting could widen the pad-substrate gap, weakening all potentially involved mechanisms.

The enhanced adhesion on rough substrates by light wetting has been explained by 'filling' of substrate cavities and by the preservation of the liquid bridge (i.e. capillary adhesion; [43]). However, stronger capillary adhesion may also lead to a reduction of the pad-substrate gap width or an enlargement of the area of dry contact, hence indirectly enhancing other mechanisms of force generation, which are likely to be weakened at the tested roughnes levels of ca. 30-60 $\mu \mathrm{m}[10,97]$.

'Dry' adhesion mechanisms The enhanced adhesion on substrates with asperities $\lesssim 6 \mu \mathrm{m}$ may be explained by mechanical interlocking [97]. One could also attribute this finding to an enhanced contact area and vdW forces. The seemingly continuous decrease of $\alpha_{\perp}$ shown in Fig. 11 for $R_{\mathrm{a}}=2-60 \mu \mathrm{m}$ suggests a continuous reduction of the effective 'dry' contact area and vdW forces with increasing roughness (in contrast to an expected drop of capillary adhesion because of meniscus cavitation at a critical roughness). Also, the weakened adhesion on rough (i.e. a reduced effective contact area) as well as wetted smooth substrates (i.e. a wider pad-substrate gap and a reduced Hamaker constant) and the scaling of tenacity with the number of beads contaminating the pad-substrate gap (i.e. a reduced effective contact area) reported in [71] are consistent with vdW forces. The enhanced adhesion on very rough substrates $\left(R_{\mathrm{a}} \geq 0.2 \mathrm{~mm}\right)$ might be created by the whole toe pad interlocking with macroscopic substrate projections.

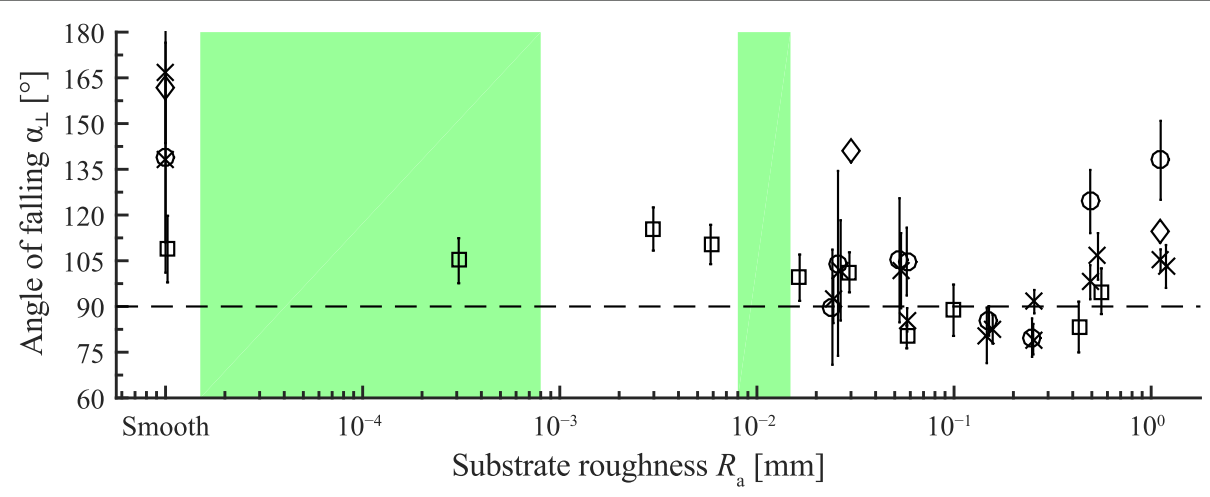

Fig. 11 Variation of the falling angle $\alpha_{\perp}$ with substrate roughness $R_{a}$ on an inclined, dry substrate (circles from Fig. 5 in [43], Hyla microcephala; crosses from Fig. 8A in [9], Colostethus trinitatis; diamonds from Fig. 3B in [10], Rhacophorus pardalis; squares from Fig. 1B in [97], Litoria caerulea). Green areas denote the diameter range of nanopillars (left) and epidermal cells (right) reported in the main text. Dashed line: Falling angles below $90^{\circ}$ show the lack of adhesive abilities. Most roughness values mentioned in the references are approximations and do not originate from measurements 
Friction mechanisms Similar to adhesion, the increase of friction on microrough compared to smooth substrates may originate from mechanical interlocking [97]. Alternatively, an increase in effective contact area and vdW forces could explain this finding. The negative correlation between friction and the mucus volume present in the pad-substrate gap suggested by the findings of Endlein et al. [10] and Zhang et al. [112] may originate from the inverse scaling of hydrodynamic friction with mucus film thickness. Alternatively, more (and stronger) dry contacts could explain this observation.

\section{Behavioural adaptations and attachment control}

Studying the use of a pad (and of other body parts) during locomotion provides insight into the dynamic mechanisms of force generation and attachment control in tree frogs. For example, the digits in the forelimbs perform a proximal pulling movement during attachment in normal walking $[6,62]$. Such movements increase the attachment force [39], possibly because of an increased contact area, enhanced mucus spread, a more uniform load distribution, or pad cleaning [71].

On an increasingly tilted substrate, $L$. caerulea begins to splay the initially adducted limbs until all appendages are maximally extended $[10,113]$. Limb splaying reduces the angle $\theta_{\mathrm{L}}$ between substrate and pulling force, which is aligned approximately with the limb, and thus increases the force at which the pad peels off (see Additional file 1); sliding of the limbs and an increase of $\theta_{\mathrm{L}}$ because of gravity result in the need to continuously reposition the fore- and hindlimbs, which explains the 'dance-like' movements of tree frogs on overhanging substrates [10].

During attachment, tree frogs rely not only on their pads but also on portions of belly and thighs to create contact forces [6]. At a slope of $90^{\circ}$, belly and thigh form $73 \%$ of the total contact area [10]. However, on an overhanging substrate the contact area is largely formed by the toe pads [10]. Torrent frogs show a different behaviour, with an increasing contribution of belly and thighs to the contact area with an increase of the substrate inclination from $90^{\circ}$ to $180^{\circ}$ [10], highlighting the importance of considering animal behaviour while studying the attachment performance of whole animals.

The toe pads detach from the substrate during normal walking in a peeling motion from posterior to anterior [6]. Detachment is probably controlled by the tendons and muscles [6], and peeling occurs passively when the pad is pulled from the substrate. On a vertical substrate, tree frogs that are rotated around the sagittal body axis realign their bodies towards the vertical axis, presumably to avoid passive peeling $[6,40]$.

\section{Conclusions and perspectives}

Studies on morphology, material, and attachment forces of the toe pads of tree frogs have contributed considerably to the understanding of the attachment of these animals. We offer a systematic review of these studies, facilitating an in-depth discussion of the mechanisms involved in the generation, transmission, and control of attachment forces in the toe pads. Research which integrates contributions from experimental and computational biomechanics, physics, biochemistry, morphology, ecology, phylogenetics, and biomimetics is required to further deepen our understanding of tree frog attachment. Simultaneously, the discussion on tree frog attachment should be extended beyond isolated theories and pad features. An overarching model is needed, which integrates the functional demands on the toe pads, the pad morphology, and the various mechanisms contributing to time-dependent adhesion and friction. Here, the formulation and testing of a systematic series of hypotheses may help to identify the mechanisms to be considered. Moreover, we emphasise the role of friction in tree frog attachment. Recent works (e.g. [25, 39, 69, 113]) have highlighted the importance of friction in tree frog attachment and future studies on toe pad friction may advance the understanding of the functioning of tree frog toe pads. Due to the diversity of the involved phenomena, achieving an understanding of tree frog attachment arguably is even more complicated than for the attachment in geckos. Below, we outline possible contributions from various disciplines which may improve our understanding of tree frog attachment.

We argue that the pad-substrate contact area has been overestimated in previous research [80, 97], pointing towards an underestimation of the adhesive and frictional performance of tree frogs. In addition, tenacity and shear stress of so-called subarticular/digital tuberclesmore proximal regions of digital epidermis covered with surface structures similar to those on the pads-were measured to be on average 3.2-8.8 times higher compared to the pads [39]. The difference in attachment performance between the toe pads and tubercles is not yet explained.

It is likely that tree frogs rely on several attachment mechanisms, and that the relative importance of these mechanisms varies with the circumstances [24], because tree frogs have to interact with a wide diversity of natural surfaces, requiring static and dynamic, adhesive and frictional, reversible, and repeatable force generation. In addition, tree frog species vary greatly in size (with ranges of snout-vent-length and body mass covering up to two orders of magnitude; [42]). Next to variations of substrate properties, the attachment apparatus of tree frogs has to deal with this scaling.

A liquid bridge in the pad-substrate gap most likely enables capillary adhesion. Current analytical plate-plate 
models overpredict the generated capillary adhesion by several orders of magnitude, sphere-plate models do not predict an area-scaling of adhesion, and experimental findings (e.g. pad-substrate gap widths $\leq 5 \mathrm{~nm}$ and increased adhesion on microrough compared to smooth substrates) indicate the involvement of other adhesion mechanisms. To directly evaluate the applicability of current models of capillary forces in tree frog attachment, we propose the simultaneous measurement of the capillary pressure within the meniscus and of meniscus parameters such as height (i.e. curvature), diameter, and contact angle.

Hydrodynamic adhesion is hard to predict by analytical models. This mechanism seems more of a hindrance for the animal (e.g. slower attachment and detachment), rather than a primary mechanism of adhesion. We suggest a combination of the visualisation of the mucus flow under a real pad (e.g. via micro-particle-imagevelocimetry), the development of a computational fluid dynamics model including fluid-solid interactions, and measurements on artificial hierarchically structured surfaces to further investigate the mucus flow dynamics and the resulting hydrodynamic forces in tree frogs.

A sensitivity analysis shows that even in a conservative computation van der Waals (vdW) forces could contribute to tree frog adhesion. Measurement of the attachment performance on substrates with similar surface energies but different subsurface energies, as done for geckos [94], may help to conclude on the possibility of vdW forces contributing to tree frog attachment.

Mechanical interlocking and suction cannot be ruled out as additional adhesion mechanisms. Variation of the environmental pressure should directly affect the hypothetical suction of tree frog toe pads. In line with previous experiments [24,62], we suggest single pad force measurements in a pressure chamber to test whether suction is present.

A simultaneous measurement of the three-dimensional contact force exerted by a single pad over a whole step cycle, contact area, and pad deformation is still missing. Such an observation is crucial for enhancing the understanding of the fundamentals of tree frog attachment. In such an experiment, control-or at least reportingof experimental parameters such as normal load, sliding speed, contact area, or gap width is crucial, as presented in recent studies (e.g. [39, 114]). This also includes a characterisation of the used test substrates and of environmental conditions (e.g. temperature and air humidity). Also, the amount of mucus in the pad-substrate gap should get controlled, for example by bringing the pad in contact with a glass slide under defined conditions (as shown for insects $[79,115])$. Comprehensive control and reporting of the experimental conditions may facilitate future meta-analyses on the attachment performance of tree frogs.
With respect to the effects of the variation of substrate properties on tree frog attachment, only roughness has been tested extensively. In geckos, the effects of variations in surface and subsurface energy as well as stiffness of the substrate have been analysed experimentally $[94,116]$. Analogously, we suggest systematic variations of substrate properties (e.g. roughness and surface energy), properties of the wetting liquid (e.g. surface tension and viscosity), and simultaneous measurements of adhesion, friction, and contact area of single pads in combination with variations of preload, sliding speed, and detachment speed, to determine the full range of the attachment performance of tree frogs. In particular, a parametric friction study with control of normal load, sliding speed, and gap width would help to establish the dependence of friction on the Stribeck number (i.e. the Stribeck curve). Such a study could give a better understanding of the involved tribological mechanisms (e.g. the role of the mucus in friction) and might allow for conclusions on liquid and material properties [98] of the pad by comparison to Stribeck curves of known systems.

In contrast to geckos, tree frogs secrete mucus, which presumably fulfils various functions: (i) epidermal water and oxygen uptake, (ii) capillary and hydrodynamic force generation, (iii) avoidance of pad stiffening and a reduced conformability, and (iv) lubrication and hence reduction of abrasive wear. Studying the mucus properties is central to elucidating tree frog attachment.

Considering the effects of variations of roughness and wetting on tree frog attachment, we propose an interplay of vdW and capillary forces depending of substrate roughness: On low-roughness substrates $\left(R_{\mathrm{a}} \leq 10-20 \mu \mathrm{m}\right)$, vdW forces could be dominant and any liquid between pad and substrate would weaken this adhesion component. On rougher substrates, a liquid filled pad-substrate gap may support capillary adhesion, which then could (partially) compensate for the expected reduction of vdW forces. Based on this hypothetical interplay, we predict a trade-off in force generation based on capillarity and vdW interactions: Liquid filling the pad-substrate gap enhances capillary forces, but too much liquid reduces the Hamaker constant and vdW interactions.

Morphology and material composition of the toe pad suggest a high conformability to the substrate (i.e. reduced pad-substrate gap width and enhanced effective contact area) and consequently the importance of dry contacts: The hierarchical surface pattern on the ventral pad surface presumably reduces the effective bending stiffness of the surface and increases the wetted area of the pad. The intercellular channel network, the convex pad curvature, and macroscopic grooves on the ventral epidermis may facilitate viscosity-dominated drainage of interstitial liquids and gap-closure in the central part of the pad, 
and inertia-dominated drainage in the grooves and in the peripheral contact region, unaffected by the presence of epidermal surface structures (similar to, for example, car tires; [83]). Furthermore, the pads are very soft, enabling the conformation to a rough substrate. Barnes et al. [47] reported a negative spatial stiffness gradient from the pad surface towards deeper tissues. Analysing the shape of this gradient may help to understand the conformability and distribution of mechanical stresses within the pad epidermis. Considering the load transmitting elements such as tonofilaments, we expect a higher tensile stiffness than the compressive stiffnesses reported in Table 1 . The effects of such a variable elastic modulus or of potential nonHookean material properties (e.g. strain stiffening) on force generation are unknown.

The trajectories of the epidermal tonofilaments presumably facilitate force transmission through the epidermis, but how are forces transmitted from there to the phalanx and to other body parts? We suggest a detailed morphological analysis (employing histology, immunohistochemistry, and micro-computer-tomography) of tree frogs' toe pads, with focus on force-transmitting structures, such as cytoskeletal elements, connective tissue, and muscular tissue. Such an analysis may show (i) where exactly contact forces are generated, (ii) which types of loading are dominant in the pads, and (iii) whether shear stiffening, as observed in geckos [28, 117], is common in both dry and wet adhesives. We expect that force transmission within the epidermis limits local stress concentrations, enhancing adhesion [2].

Little is known about active components and attachment control in the toe pads. Can tree frogs actively modify the geometry of the epidermal channels to control, for example, hydrodynamic force generation? Do the pads facilitate energy recovery during take offs from compliant substrates [118]? The muscular complex in the limbs of tree frogs suggests that tree frogs can control alignment of the pads and parameters such as normal and shear loading forces and speeds, thus regulating attachment force generation.

Next to capillary friction and suction (see Additional file 1), there may be other attachment mechanisms that have not yet been identified or have been only hypothesised. For example, Bijma et al. [80] explained the high friction of toe pads wrapped around curved substrates by capstan friction (i.e. the increased holding force of a rope wrapped around a winch). Friction of a soft pad could also partially arise from pad deformations due to surface tension at the three-phase contact line. During pad sliding, a movement of the contact line might induce dynamic pad deformations leading to energy dissipation in the potentially viscoelastic pad [119]. Furthermore, viscoelasticity of the soft pads may affect friction independently of the presence of a meniscus [120]: In so-called rubber friction, substrate roughnes causes dynamic deformations of the toe pad. Thus, during sliding, energy is continuously dissipated in the material, which can be seen as friction resisting sliding $[9,95]$.

The toe pads of tree frogs can serve as a model system for the design of biomimetic adhesives, inspiring novel versatile attachment solutions. A deeper understanding of the attachment mechanisms and functional advantages of the hierarchically structured ventral pad surface (i.e. epidermal cells and nanopillars) could further advance the design of biomimetic adhesives. In this light, we propose a comparative examination of intraspecific differences in habitat, attachment performance, and morphology of the whole pad as well as the epidermal surface structures, as done in geckos $[121,122]$. One could expect, for example, fore-hindlimb differences in morphology and attachment performance because of different functions (hindlimbs serve in jumping [123]; forelimbs serve as shock absorbers [124]). Furthermore, adhesion was reported to correlate with cell size [42]. Although not fully substantiated, the examination of such a correlation may lead to new insights in the role of the different attachment mechanisms in tree frogs. Are cell geometry, size of the intercellular channels, or the stiffness of a cell (or a combination of these features) causal factors affecting attachment? What is the optimal geometry of the polygonal surface structures? The hierarchical surface structures on the ventral toe pad epidermis, the scaling of attachment performance with cell size, and the potential presence of vdW forces in tree frog attachment may also hint towards the working of contact splitting (i.e. the increase of attachment force resulting from subdivision of the contact area), which has been discussed for various biological and technical attachment systems [2, 60, 125-127]. Further work is required to elucidate the importance of contact splitting in tree frogs. We expect that the design of biomimetic adhesives will benefit significantly from addressing these issues.

\section{Endnotes}

${ }^{1}$ 'Holding' and 'attaching' synonymously describe combinations of adhesion and friction, whereas 'adhering' exclusively refers to adhesion.

2'Wetting': the presence of liquid on a substrate.

\section{Additional file}

Additional file 1: Symbols and abbreviations. List of symbols, List of abbreviations. Morphology and material properties of a toe pad. Geometrical model of the surface of the ventral toe pad epidermis, Fibre-matrix analogy of a toe pad, Scaling of tenacity with snout-vent-length. Attachment performance of tree frogs. The rotating platform experiment, Capillary adhesion of deformable objects, Capillary friction, Suction, Kendall peeling model, Johnson-Kendall-Roberts model. (DOCX $125 \mathrm{~kb}$ ) 


\section{Acknowledgements}

We thank D Labonte, P van Assenbergh and the journal club team of the Experimental Zoology Group, Wageningen University \& Research, for helpful comments on the manuscript. We are grateful to WJP Barnes, D Labonte, T Endlein and M Kappl for constructive discussions on tree frog attachment. Also, we wish to express our gratitude towards D Labonte for providing relevant literature from the $19^{\text {th }}$ century.

\section{Funding}

This work is part of the research programme "Secure and gentle grip of delicate biological tissues" with project number 13353, which is financed by the Netherlands Organisation for Scientific Research (NWO).

\section{Availability of data and materials}

The datasets used and analysed in this review are available in the cited literature and from the corresponding author on reasonable request.

\section{Authors' contributions}

JKAL compiled the references, analysed the data, created the figures and drafted/revised the manuscript. DD, MK and JLVL commented and revised previous versions of the figures and the manuscript. All authors read and approved the final manuscript.

\section{Ethics approval and consent to participate}

Not applicable.

\section{Consent for publication}

Not applicable.

\section{Competing interests}

The authors declare that they have no competing interests.

\section{Publisher's Note}

Springer Nature remains neutral with regard to jurisdictional claims in published maps and institutional affiliations.

\section{Author details}

${ }^{1}$ Experimental Zoology Group, Department of Animal Sciences, Wageningen University \& Research, De Elst 1, 6708 WD Wageningen, The Netherlands. ${ }^{2}$ Department of BioMechanical Engineering, Faculty of Mechanical, Maritime and Materials Engineering, Delft University of Technology, Mekelweg 2, 2628 CD Delft, The Netherlands. ${ }^{3}$ Physical Chemistry and Soft Matter, Department of Agrotechnology and Food Sciences, Wageningen University \& Research, Stippeneng 4, 6708 WE Wageningen, The Netherlands.

\section{Received: 8 December 2017 Accepted: 29 June 2018}

Published online: 23 August 2018

\section{References}

1. Peattie AM. Functional demands of dynamic biological adhesion: an integrative approach. J Comp Physiol B. 2009;179:231-9.

2. Labonte D, Federle W. Scaling and biomechanics of surface attachment in climbing animals. Phil Trans R Soc B. 2015;370:1-17.

3. Gorb SN. Biological attachment devices: exploring nature's diversity for biomimetics. Phil Trans R Soc A. 2008;366:1557-74.

4. Niewiarowski PH, Stark AY, Dhinojwala A. Sticking to the story: outstanding challenges in gecko-inspired adhesives. J Exp Biol. 2016;219(7):912-9.

5. Wolff JO, Gorb SN. In: Gorb S, editor. Attachment Structures and, Adhesive Secretions in Arachnids. vol. 7. Cham, Switzerland: Springer; 2016.

6. Hanna G, Barnes WJP. Adhesion and detachment of the toe pads of tree frogs. J Exp Biol. 1991;155(1):103-25.

7. Endlein T, Barnes WJP. Wet Adhesion in Tree and Torrent Frogs. In: Bhushan B, editor. Encyclopedia of Nanotechnology. Dordrecht: Springer; 2015. p. 1-20.

8. Ohler A. Digital pad morphology in torrent-living ranid frogs. Asiat Herpetol Res. 1995;6:85-96.

9. Barnes WJP, Smith J, Oines C, Mundl R. Bionics and wet grip. Tire Technol Int. 2002;56-60.
10. Endlein T, Barnes WJP, Samuel DS, Crawford NA, Biaw AB, Grafe U. Sticking under wet conditions: the remarkable attachment abilities of the torrent frog, Staurois guttatus. PLoS ONE. 2013;8(9):1-12.

11. Drotlef DM, Appel E, Peisker H, Dening K, del Campo A, Gorb SN, et al. Morphological studies of the toe pads of the rock frog, Staurois parvus (family: Ranidae) and their relevance to the development of new biomimetically inspired reversible adhesives. Interf Focus. 2015;5:1-11.

12. Iturri J, Xue L, Kappl M, García-Fernández L, Barnes WJP, Butt HJ, et al. Torrent frog-inspired adhesives: attachment to flooded surfaces. Adv Funct Mater. 2015;25(10):1499-505.

13. Siedlecki M. Zur Kenntnis des javanischen Flugfrosches. Biologisches Centralblatt. 1909;29:704-15. Available from: http://www. biodiversitylibrary.org/page/5322635\#page/724/mode/1up.

14. Liem SS. The Morphology, Systematics, and Evolution of The Old World Treefrogs (Rhacophoridae and Hyperoliidae). In: Williams PM, editor. Fieldiana: Zoology. vol. 57 of Zoological Series. Chicago: Field Museum of Natural History; 1970.

15. Duellman WE, Trueb L. Biology of Amphibians. Baltimore: The Johns Hopkins University Press; 1994

16. Faivovich J, Haddad CFB, Garcia PCA, Frost DR, Campbell JA, Wheeler WC. Systematic review of the frog family Hylidae, with special reference to Hylinae: phylogenetic analysis and taxonomic revision. Bull Am Mus Nat Hist. 2005;294:1-240.

17. Wells KD. The Ecology \& Behaviour of Amphibians. Chicago: The University of Chicago Press; 2007.

18. Green DM. Treefrog toe pads: comparative surface morphology using scanning electron microscopy. Can J Zool. 1979;57:2033-46.

19. McAllister W, Channing A. Comparison of toe pads of some southern African climbing frogs. S Afr J Zool. 1983;18(2):110-4.

20. Lee WJ, Lue CH, Lue KY. The SEM comparative study on toe pads among 11 species of tree frogs from Taiwan. BioFormosa. 2001;36:27-36.

21. Barnes WJP, Baum M, Peisker H, Gorb SN. Comparative cryo-SEM and AFM studies of hylid and rhacophorid tree frog toe pads. J Morphol. 2013;274:1384-96

22. Scholz I, Barnes WJP, Smith JM, Baumgartner W. Ultrastructure and physical properties of an adhesive surface, the toe pad epithelium of the tree frog, Litoria caerulea White. J Exp Biol. 2009;212:155-62.

23. Ernst W. The digital pads of the tree frog, Hyla cinerea. I. The epidermis. Tissue Cell. 1973:5(1):83-96.

24. Emerson SB, Diehl D. Toe pad morphology and mechanisms of sticking in frogs. Biol J Linn Soc. 1980;13:199-216.

25. Federle W, Barnes WJP, Baumgartner W, Drechsler P, Smith JM. Wet but not slippery: boundary friction in tree frog adhesive toe pads. J R Soc Interface. 2006;3(10):689-97.

26. Autumn K, Liang YA, Hsieh ST, Zesch W, Chan WP, Kenny TW, et al. Adhesive force of a single gecko foot-hair. Nature. 2000;405:681-5.

27. Autumn K, Sitti M, Liang YA, Peattie AM, Hansen WR, Sponberg S, et al. Evidence for van der Waals adhesion in gecko setae. Proc Natl Acad Sci USA. 2002;99(19):12252-6.

28. Bartlett MD, Croll AB, King DR, Paret BM, J ID, Crosby AJ. Looking beyond fibrillar features to scale gecko-like adhesion. Adv Mater. 2012;24(8):1078-83.

29. Bartlett MD, Croll AB, Crosby AJ. Designing bio-inspired adhesives for shear loading: from simple structures to complex patterns. Adv Funct Mater. 2012;22:4985-92.

30. Bartlett MD, Crosby AJ. High capacity, easy release adhesives from renewable materials. Adv Mater. 2014;26:3405-9.

31. Ernst W. The digital pads of the tree frog, Hyla cinerea. II. The mucous glands. Tissue Cell. 1973;5(1):97-104.

32. Hertwig I, Sinsch U. Comparative toe pad morphology in marsupial frogs (Genus Gastrotheca): Arboreal versus ground-dwelling species. Copeia. 1995;1995(1):38-47.

33. Siedlecki M. Die Haftballen des javanischen Flugfrosches. Bull Acad Sci, Krakow (B). 1910593-606. Available from: http://www.biodiversitylibrary. org/bibliography/13192\#/summary.

34. Nakano M, Saino T. Light and electron microscopic analyses of the high deformability of adhesive toe pads in white's tree frog, Litoria caerulea. J Morphol. 2016;277:1509-16.

35. Linnenbach M. Zum Feinbau der Haftscheiben von Hyla cinerea (Schneider, 1799) (Salientia: Hylidae). Salamandra. 1985;21(1):81-5.

36. Ba-Omar TA, Downie JR, Barnes WJP. Development of adhesive toe-pads in the tree-frog (Phyllomedusa trinitatis). J Zool. 2000;250:267-82. 
37. Mizuhira V. The digital pads of rhacophorid tree-frogs. J Electron Microsc. 2004;53(1):63-78.

38. Chakraborti S, Nag TC, Das D, Sanyal Chatterjee T, De SK. Cytokeratin localization in toe pads of the anuran amphibian Philautus annandalii (Boulenger, 1906). Tissue Cell. 2014;46:165-9.

39. Endlein T, Ji A, Yuan S, Hill I, Wang H, Barnes WJP, et al. The use of clamping grips and friction pads by tree frogs for climbing curved surfaces. Proc R Soc B Biol Sci. 2017;284:1-9.

40. Barnes WJP, Oines C, Smith JM. Whole animal measurements of shear and adhesive forces in adult tree frogs: insights into underlying mechanisms of adhesion obtained from studying the effects of size and scale. J Comp Physiol A. 2006;192(11):1179-91.

41. Smith JM, Barnes WJP, Downie JR, Ruxton GD. Adhesion and allometry from metamorphosis to maturation in hylid tree frogs: a sticky problem. J Zool. 2006;270:372-83.

42. Smith JM, Barnes WJP, Downie JR, Ruxton GD. Structural correlates of increased adhesive efficiency with adult size in the toe pads of hylid tree frogs. J Comp Physiol A. 2006;192(11):1193-204.

43. Barnes WJP. Tree frogs and tire technology. Tire Technol Int. 1999;(1999): 42-7.

44. Noble GK, Jaeckle ME. The digital pads of the tree frogs. A study of the phylogenesis of an adaptive structure. J Morphol Physiol. 1928;45(1): 259-92.

45. Richards CM, Carlson BM, Connelly TG, Rogers SL, Ashcraft E. A scanning electron microscopic study of differentiation of the digital pad in regenerating digits of the Kenyan reed frog, Hyperolius viridiflavus ferniquei. J Morphol. 1977;153:387-96.

46. Green DM. Adhesion and the Toe-Pads of Treefrogs. Copeia. 1981;1981: 790-6.

47. Barnes WJP, Goodwyn PJP, Nokhbatolfoghahai M, Gorb SN. Elastic modulus of tree frog adhesive toe pads. J Comp Physiol A. 2011;197(10): 969-78.

48. Gu Z, Li S, Zhang F, Wang S. Understanding Surface Adhesion in Nature: A Peeling Model. Adv Sci. 2016;3:1-13.

49. Nokhbatolfoghahai M. Toe-pad morphology in White's tree frog, Litoria caerulea (Family Hylidae). Iran J Sci Technol. 2013;37(4):491-9.

50. Leydig F. Ueber Organe eines sechsten Sinnes. Dresden: E. Blochmann \& Sohn; 1868.

51. Welsch U, Storch V, Fuchs W. The fine structure of the digital pads of rhacophorid tree frogs. Cell Tissue Res. 1974;148(3):407-16.

52. Dewitz H. Ueber das verschiedene Aussehen der gereizten und ruhenden Drüsen im Zehenballen des Laubfrosches. Biologisches Zentralblatt. 1883;3:558-560. Available from: http://www. biodiversitylibrary.org/item/27783.

53. Chen $H$, Zhang L, Zhang D, Zhang P, Han Z. Bioinspired surface for surgical fraspers based on the strong wet friction of tree frog toe pads. ACS Appl Mater Interfaces. 2015;7(25):13987-95.

54. Green DM. Size Differences in adhesive toe-pad cells of treefrogs of the diploid-polyploid Hyla versicolor Complex. J Herpetol. 1980;14(1):15-19.

55. Chakraborti S, Das D, De SK, Nag TC. Structural organization of the toe pads in the amphibian Philautus annandalii (Boulenger, 1906). Acta Zool. 2014;95:63-72.

56. Rivero JA, Oliver L, de los Angeles Irizarry M. Los discos digitales de tres Eleutherodactylus (Anura, Leptodactylidae) de Puerto Rico, con anotaciones sobre los mecanismos de adhesion en las ranas. Carribean J Sci. 1987;23(2):226-37.

57. Blackwall J. On the means by which various animals walk on the vertical surfaces of highly polished bodies. Ann Mag Nat Hist. 1845;15:115-9.

58. Green DM, Carson J. The adhesion of treefrog toe-pads to glass: cryogenic examination of a capillary adhesion system. J Nat Hist. 1988;22:131-5.

59. Green DM, Simon MP. Digital Microstructure in ecologically diverse sympatric microhylid frogs, genera Cophixalus and Sphenophryne (Amphibia : Anura), from Papua New Guinea. Aust J Zool. 1986;34: 135-45.

60. Arzt E, Gorb S, Spolenak R. From micro to nano contacts in biological attachment devices. Proc Natl Acad Sci USA. 2003;100(19):10603-6.

61. Manzano AS, Abdala V, Herrel A. Morphology and function of the forelimb in arboreal frogs: specializations for grasping ability? J Anat. 2008;213:296-307.

62. Schuberg A. Über den Bau und die Funktion der Haftapparate des Laubfrosches. Arbeiten aus dem Zoologisch-Zootomischen Institut in
Würzburg. 1891;10(1):57-119. Available from https://archive.org/details/ arbeitenausdemzo10semp.

63. Gadow H. Amphibia and Reptiles. London: MacMillan and Co.; 1909.

64. Afferante L, Heepe L, Casdorff K, Gorb SN, Carbone G. A theoretical characterization of curvature controlled adhesive properties of bio-inspired membranes. Biomimetics. 2016;1(1):3.

65. v. Wittich. Der Mechanismus der Haftzehen von Hyla arborea. Archiv für Anatomie, Physiologie und Wissenschaftliche Medicin. 1854;170-184. Available from: http://www.biodiversitylibrary.org/item/50228\#page/7/ mode/1up.

66. Manzano AS, Fabrezi M, Vences M. Intercalary elements, treefrogs, and the early differentiation of a complex system in the Neobatrachia. Anat Rec. 2007;290(12):1551-67.

67. Vandebergh W, Maex M, Bossuyt F, Van Bocxlaer I. Recurrent functional divergence of early tetrapod keratins in amphibian toe pads and mammalian hair. Biol Lett. 2013;9:1-4.

68. Vincent JFV, Wegst UGK. Design and mechanical properties of insect cuticle. Arthropod Struct Dev. 2004;33:187-99.

69. Kappl M, Kaveh F, Barnes WJP. Nanoscale friction and adhesion of tree frog toe pads. Bioinspiration Biomimetics. 2016;11(3).

70. Drotlef DM, Stepien L, Kappl M, Barnes WJP, Butt HJ, del Campo A. Insights into the adhesive mechanisms of tree frogs using artificial mimics. Adv Funct Mater. 2013;23:1137-46.

71. Crawford N, Endlein T, Barnes WJP. Self-cleaning in tree frog toe pads; a mechanism for recovering from contamination without the need for grooming. J Exp Biol. 2012;215:3965-72.

72. Tyler MJ, Davies M. Family Hylidae. In: Glasby CG, Ross GJB, Beesley PL, editors. Fauna of Australia. vol. 2A. Canberra: Australian Government Publishing Service; 1993. p. 1-15.

73. Hill IDC, Dong B, Barnes WJP, Ji A, Endlein T. The biomechanics of tree frogs climbing curved surfaces: a gripping problem. J Exp Biol. 2018;221:1-10

74. Holdgate MW. The wetting of insect cuticles by water. J Exp Biol. 1955;32:591-617.

75. Koch K, Bhushan B, Barthlott W. Diversity of structure, morphology and wetting of plant surfaces. Soft Matter. 2008;4:1943-63.

76. Stebbins RC, Cohen NW. A Natural History of Amphibians. Princeton: Princeton University Press; 1995.

77. Tracy CR, Laurence N, Christian KA. Condensation onto the skin as a means for water gain by tree frogs in tropical Australia. Am Nat. 2011;178(4):553-8.

78. Puthoff JB, Prowse MS, Wilkinson M, Autumn K. Changes in materials properties explain the effects of humidity on gecko adhesion. J Exp Biol. 2010;213:3699-704.

79. Bullock JMR, Drechsler P, Federle W. Comparison of smooth and hairy attachment pads in insects: friction, adhesion and mechanisms for direction-dependence. J Exp Biol. 2008;211:3333-43.

80. Bijma NN, Gorb SN, Kleinteich T. Landing on branches in the frog Trachycephalus resinifictrix (Anura: Hylidae). J Comp Physiol A. 2016;202:267-76.

81. Drechsler PH. Mechanics of adhesion and friction in stick insects and tree frogs. Würzburg, Germany: Julius-Maximilians-Universität Würzburg; 2008. Available from: http://opus.bibliothek.uni-wuerzburg.de/ frontdoor/index/index/docld/2293.

82. Autumn K, Peattie AM. Mechanisms of adhesion in geckos. Integr Comp Biol. 2002;42(6):1081-90.

83. Persson BNJ. Wet adhesion with application to tree frog adhesive toe pads and tires. J Phys Condens Matter. 2007;19(37):1-16.

84. Butt HJ, Kappl M. Normal capillary forces. Adv Colloid Interf Sci. 2009;146:48-60.

85. de Gennes PG, Brochard-Wyart F, Quéré D. Capillarity and Wetting Phenomea: Drops, Bubbles, Pearls, Waves. New York: Springer; 2004

86. Butt HJ, Barnes WJP, del Campo A, Kappl M, Schönfeld F. Capillary forces between soft, elastic spheres. Soft Matter. 2010;6:5930-6.

87. Wexler JS, Heard TM, Stone HA. Capillary bridges between soft substrates. Phys Rev Lett. 2014;112:066102-1-5.

88. Stefan J. Versuche über die scheinbare Adhäsion. Anzeiger der Kaiserlichen Akademie zu Wien. 1874;12:316-8.

89. Reynolds $\mathrm{O}$. On the theory of lubrication and its application to $\mathrm{Mr}$. Beauchamp Tower's experiments, including an experimental determination of the viscosity of olive oil. Philos Trans R Soc Lond. 1886;177:157-234. 
90. Cox RG, Brenner H. The slow motion of a sphere through a viscous fluid towards a plane surface-ll Small gap widths, including inertial effects. Chem Eng Sci. 1967;22:1759-77.

91. Kaveh F, Ally J, Kappl M, Butt HJ. Hydrodynamic force between a sphere and a soft, elastic surface. Langmuir. 2014;30:11619-24.

92. Landau LD, Lifshitz EM. Fluid Mechanics. 2nd ed. Oxford: Pergamon; 1987.

93. Tulchinsky A, Gat AD. Viscous-poroelastic interaction as mechanism to create adhesion in frogs' toe pads. J Fluid Mech. 2015;775:288-303.

94. Loskill P, Puthoff J, Wilkinson M, Mecke K, Jacobs K, Autumn K. Macroscale adhesion of gecko setae reflects nanoscale differences in subsurface composition. J R Soc Interface. 2013;10:1-8.

95. Popov V. Contact Mechanics and Friction: Physical Principles and Applications. Heidelberg, Dordrecht, London: Springer; 2010.

96. Israelachvili JN. Intermolecular and Surface Forces. 3rd ed. Amsterdam: Elsevier; 2011.

97. Crawford N, Endlein T, Pham JT, Riehle M, Barnes WJP. When the going gets rough - studying the effect of surface roughness on the adhesive abilities of tree frogs. Beilstein J Nanotechnol. 2016;7:2116-31.

98. Pitenis AA, Urueña JM, Schulze KD, Nixon RM, Dunn AC, Krick BA, et al. Polymer fluctuation lubrication in hydrogel gemini interfaces. Soft Matter. 2014;10:8955-62.

99. Gupta R, Fréchette J. Measurement and scaling of hydrodynamic interactions in the presence of draining channels. Langmuir. 2012;28: 14703-12.

100. Dhong C, Fréchette J. Coupled effects of applied load and surface structure on the viscous forces during peeling. Soft Matter. 2015;11: 1901-9.

101. Barnes WJP, Pearman J, Platter J. Application of peeling theory to tree frog adhesion, a biological system with biomimetic implications. E-Newsletters for Science and Technology, Published by European Academy of Sciences (EAS). 2008;1(1):1-2.

102. Nachtigall W. Biological Mechanisms of Attachment: The Comparative Morphology and Bioengineering of Organs for Linkage, Suction, and Adhesion. 1st ed. Berlin, Heidelberg: Springer Verlag; 1974.

103. Drechsler P, Federle W. Biomechanics of smooth adhesive pads in insects: influence of tarsal secretion on attachment performance. J Comp Physiol A. 2006;192:1213-22.

104. Barnes WJP. Adhesion in Wet Environments: Frogs. In: Bhushan B, editor Encyclopedia of Nanotechnology. Dordrecht: Springer; 2012. p. 70-83.

105. Parsegian VA. Van der Waals Forces. New York: Cambridge University Press; 2006.

106. Leroy S, Charlaix E. Hydrodynamic interactions for the measurement of thin film elastic properties. J Fluid Mech. 2011;674:389-407.

107. Pilkington GA, Gupta R, Fréchette J. Scaling hydrodynamic boundary conditions of microstructured surfaces in the thin channel limit. Langmuir. 2016;23:2360-8.

108. Dai Z, Gorb SN, Schwarz U. Roughness-dependent friction force of the tarsal claw system in the beetle Pachnoda marginata (Coleoptera, Scarabaeidae). J Exp Biol. 2002;205:2479-88.

109. Bullock JMR, Federle W. The effect of surface roughness on claw and adhesive hair performance in the dock beetle Gastrophysa viridula. Insect Sci. 2011;18:298-304.

110. Wu NC, Cramp RL, Franklin CE. Living with a leaky skin: upregulation of ion transport proteins during sloughing. J Exp Biol. 2017;220:2026-35.

111. Brehm AE. Brehms Tierleben: allgemeine Kunde des Tierreichs. vol. 7. 3rd ed. In: Pechuel-Loesche E, editor. Leipzig, Wien: Bibliographisches, Institut; 1892. Available from: http://www.biodiversitylibrary.org/item/ 175102.

112. Zhang $L$, Chen $H$, Zhang $P$, Zhang D. Boundary friction force of tree frog's toe pads and bio-inspired hexagon pillar surface. Chin Sci Bull. 2016;61:2596-604

113. Endlein T, Ji A, Samuel D, Yao N, Wang Z, Barnes WJP, et al. Sticking like sticky tape: tree frogs use friction forces to enhance attachment on overhanging surfaces. J R Soc Interface. 2012;10(80):1-11.

114. Crawford NA. The biomechanics of tree frog adhesion under challenging conditions. Glasgow: University of Glasgow; 2016. Available from: http://theses.gla.ac.uk/7102/.

115. Dirks JH, Federle W. Mechanisms of fluid production in smooth adhesive pads of insects. J R Soc Interface. 2011;8:952-60.
116. Klittich MR, Wilson MC, Bernard C, Rodrigo RM, Keith AJ, Niewiarowski $\mathrm{PH}$, et al. Influence of substrate modulus on gecko adhesion. Sci Rep. 2017;7:1-10.

117. Gilman CA, Imburgia M, J Bartlett MD, King DR, Crosby AJ, Irschick DJ. Geckos as springs: Mechanics explain across-species scaling of adhesion. PLoS ONE. 2015;10(9):1-15.

118. Astley HC, Haruta A, Roberts TJ. Robust jumping performance and elastic energy recovery from compliant perches in tree frogs. J Exp Biol. 2015;218:3360-3.

119. Karpitschka S, Das S, van Gorcum M, Perrin H, Andreotti B, Snoeijer JH. Droplets move over viscoelastic substrates by surfing a ridge. Nat Commun. 2015;6:1-7.

120. Labonte D, Federle W. Rate-dependence of 'wet' biological adhesives and the function of the pad secretion in insects. Soft Matter. 2015;11: 8661-73.

121. Irschick DJ, Austin CC, Petren K, Fisher RN, Losos JB, Ellers O. A comparative analysis of clinging ability among pad-bearing lizards. Biol J Linn Soc. 1996;59:21-35.

122. Elstrott J, Irschick DJ. Evolutionary correlations among morphology, habitat use and clinging performance in Caribbean Anolis lizards. Biol J Linn Soc. 2004;83:389-98.

123. Emerson SB. Allometry and jumping in frogs: Helping the twain to meet. Evolution. 1978;32(3):551-64.

124. Nauwelaerts $S$, Aerts P. Take-off and landing forces in jumping frogs. J Exp Biol. 2006;209:66-77.

125. Jagota A, Hui CY. Adhesion, friction, and compliance of bio-mimetic and bio-inspired structured interfaces. Mater Sci Eng R. 2011;72:253-92.

126. Kamperman M, Kroner E, del Campo A, McMeeking RM, Arzt E. Functional adhesive surfaces with "gecko" effect: The concept of contact splitting. Adv Eng Mater. 2010;12:335-48.

127. Labonte D, Clemente CJ, Dittrich A, Kuo CY, Crosby AJ, Irschick DJ, et al. Extreme positive allometry of animal adhesive pads and the size limits of adhesion-based climbing. Proc Natl Acad Sci USA. 2015;113(5):1297-302.
Ready to submit your research? Choose BMC and benefit from:

- fast, convenient online submission

- thorough peer review by experienced researchers in your field

- rapid publication on acceptance

- support for research data, including large and complex data types

- gold Open Access which fosters wider collaboration and increased citations

- maximum visibility for your research: over $100 \mathrm{M}$ website views per year

At BMC, research is always in progress.

Learn more biomedcentral.com/submissions 